\title{
Differential expression profiling of $\Delta$ litR and $\triangle r p o Q$ mutants reveals insight into QS regulation of motility, adhesion and biofilm formation in Aliivibrio salmonicida
}

\author{
Miriam Khider ${ }^{1 *}$ (D) Erik Hjerde ${ }^{1,2}$, Hilde Hansen ${ }^{1}$ and Nils Peder Willassen ${ }^{1,2^{*}}$
}

\begin{abstract}
Background: The coordination of group behaviors in bacteria is achieved by a cell-cell signaling process called quorum sensing (QS). QS is an intercellular communication system, which synchronously controls expression of a vast range of genes in response to changes in cell density and is mediated by autoinducers that act as extracellular signals. Aliivibrio salmonicida, the causative agent of cold-water vibrosis in marine aquacultures, uses QS to regulate several activities such as motility, biofilm formation, adhesion and rugose colony morphology. However, little is known about either genes or detailed mechanisms involved in the regulation of these phenotypes.
\end{abstract}

Results: Differential expression profiling allowed us to define the genes involved in controlling phenotypes related to QS in A. salmonicida LFI1238. RNA sequencing data revealed that the number of expressed genes in $A$. salmonicida, $\Delta$ litR and $\Delta r p o Q$ mutants were significantly altered due to changes in cell density. These included genes that were distributed among the 21 functional groups, mainly presented in cell envelope, cell processes, extrachromosomal/foreign DNA and transport-binding proteins functional groups. The comparative transcriptome of A. salmonicida wild-type at high cell density relative to low cell density revealed 1013 genes to be either up- or downregulated. Thirty-six downregulated genes were gene clusters encoding biosynthesis of the flagellar and chemotaxis genes. Additionally we identified significant expression for genes involved in acyl homoserine lactone (AHL) synthesis, adhesion and early colonization. The transcriptome profile of $\Delta r p o Q$ compared to the wild-type revealed 384 differensially expressed genes (DEGs) that allowed us to assign genes involved in regulating motility, adhesion and colony rugosity. Indicating the importance of RpoQ in controlling several QS related activities. Furthermore, the comparison of the transcriptome profiles of $\Delta / i t R$ and $\Delta r p o Q$ mutants, exposed numerous overlapping DEGs that were essential for motility, exopolysaccharide production via syp operon and genes associated with tad operon.

Conclusion: Our findings indicate previously unexplained functional roles for LitR and RpoQ in regulation of different phenotypes related to QS. Our transcriptome data provide a better understanding of the regulation cascade of motility, wrinkling colony morphology and biofilm formation and will offer a major source for further research and analysis on this important field.

Keywords: Aliivibrio salmonicida, LitR, RpoQ, High cell density, Low cell density, Differentially expressed genes and quorum sensing

\footnotetext{
* Correspondence: miriam.khider@uit.no; nils-peder.willassen@uit.no

${ }^{1}$ Norwegian Structural Biology Centre, UiT - The Arctic University of Norway,

N-9037 Tromsø, Norway

Full list of author information is available at the end of the article
}

(c) The Author(s). 2019 Open Access This article is distributed under the terms of the Creative Commons Attribution 4.0 International License (http://creativecommons.org/licenses/by/4.0/), which permits unrestricted use, distribution, and

reproduction in any medium, provided you give appropriate credit to the original author(s) and the source, provide a link to the Creative Commons license, and indicate if changes were made. The Creative Commons Public Domain Dedication waiver (http://creativecommons.org/publicdomain/zero/1.0/) applies to the data made available in this article, unless otherwise stated. 


\section{Background}

Quorum sensing (QS) is a cell to cell communication process that allows bacteria to adjust gene expression in response to cell density [1]. The communication in QS depends on the production, accumulation and detection of signaling autoinducers such as acyl homoserine lactone (AHL) [2]. QS regulates a number of traits such as motility, biofilm formation, colonization, adhesion, virulence factor secretion and bioluminescence, which are required for survival and/or virulence in several bacteria [1]. The QS controlled activities, become costly when undertaken by an individual bacterium and are more beneficial when carried out by a group. Therefore, the QS system allows bacteria to switch between two states of gene expression: the low cell density (LCD) favoured for individuals and high cell density (HCD) favoured for groups [3-6].

Vibrio, species including the fish pathogen Aliivibrio salmonicida, are gram-negative, rod-shaped bacteria that live in different aqueous environments, including marine and freshwater [7]. Vibrios are known to regulate gene expression using QS system [8]. A. salmonicida possesses two QS systems the LuxI/R and AinS/R which are responsible for the production of eight AHLs in a cell density dependent manner [9].

Numerous studies have shown the ability of Vibrio species to move using flagella, mediating their movement to favorable environments and avoiding harmful conditions $[10,11]$. When facing unfavorable conditions, bacteria can escape by forming biofilms [12]. A biofilm is a structured microbial community, which serves as a reservoir protecting the bacteria from being destroyed by external treatments, as well as being the main approach for survival in various harsh environmental conditions [13-15]. The development of the biofilm is a complex mechanism involving several steps. In the initial step the planktonic bacterial cells attach to the abiotic or biotic surface using physical force or bacterial appendages (flagella or pilli). Following the adhesion micro-colonies form and grow further to a three-dimensional mature biofilm structure $[5,16]$. The forms of mature biofilms can vary from flat to multi-layered high mushroom-like structures, where numerous factors have been shown to influence the architecture of biofilm, including motility and extracellular polymeric substance (EPS) matrix production [4, 17]. Differing from the free-living planktonic state, cells in the biofilm are embedded in an EPS matrix, which provides strength to the interaction of the bacteria in the biofilm. EPS is mainly composed of polysaccharides in addition to proteins, lipids and nucleic acids $[14,18]$. The EPS loci have been identified in several pathogenic and symbiotic vibrios [14]. For example, A. salmonicida and Aliivibrio fischeri (A. fischeri) produces EPS-dependent biofilm and wrinkled colonies involving an 18-gene cluster known as symbiosis polysaccharides (syp) [19, 20]. In Vibrio cholerae (V. cholerae) the vibrio polysaccharide (vps) locus encodes proteins responsible for EPS production, which is associated with rugose colony morphology and three-dimensional biofilm structure [21, 22]. The regulation of EPS biosynthesis involves several transcription regulators such as QS which sense and respond in a cell density dependent manner [14]. HapR, the QS transcription regulator of $V$. cholerae regulates expression of VpsT and VpsR regulators of biofilm [23]. At LCD hapR is not expressed in turn both vpsT and $v p s R$ are upregulated allowing expression of genes involved in biofilm formation. Whereas at HCD hapR is expressed which results in $v p s T$ and $v p s R$ repression, causing the downregulation of the biofilm [23-26]. Likewise LitR (a homolog of HapR) of A. salmonicida is a negative regulator of biofilm formation and rugosity through syp repression $[19,27]$. Conversely, transcription regulators OpaR, LitR and SmcR of Vibrio parahaemolyticus (V. parahaemolyticus), A. fischeri and Vibrio vulnificus (V. vulnificus) respectively, are positive regulators of biofilm formation and colony opacity at HCD [28-31].

In our previous studies we were able to show that the inactivation of the LitR master regulator of QS enhanced biofilm formation, rugose colony morphology, adhesiveness and motility $[19,27]$. By microarray analysis we identified a number of LitR regulated genes, among these genes were genes of the syp operon (VSAL_IIO295-VSAL_IIO312) and rpoQ sigma factor (VSAL_IIO319) homologs of the A. fischeri syp and rpoQ genes $[19,32]$. The inactivation of the rpoQ gene in $A$. salmonicida LFI1238 resulted in phenotypic traits somewhat different from the $\Delta l i t R[33]$. The $\triangle r p o Q$ mutant showed reduced motility, slimy biofilm without mushroom structure and formed an early and strong rugose colony morphology [33]. Neverless we were not able to answer how LitR and RpoQ work together to regulate QS related traits. In the present study the transcriptome expression profiles of $\triangle l i t R$ and $\triangle r p o Q$ mutants were compared to the isogenic A. salmonicida LFI1238 wild-type, in order to gain a better understanding on how LitR and RpoQ work together and to identify the major differences in the gene expression profiles associated with the modulation of the QS related activities. Triplicates from each mutant were grown at low temperature $\left(8^{\circ} \mathrm{C}\right)$ and harvested at two cell densities $\left(\mathrm{LCD}, \mathrm{OD}_{600}=0.3\right.$ and $\mathrm{HCD}, \mathrm{OD}_{600}=1.2$ ). Low temperatures play an important role both in the development of cold-water vibriosis and the production of AHLs [9, 27]. Previously, we were able to show that the phenotypes exhibited by $\triangle l i t R$ and $\triangle r p o Q$ (rugosity and biofilm formation) were absent at temperatures above the threshold of disease development mainly above $14^{\circ} \mathrm{C}[19$, 
27, 33]. Moreover, the concentration of the eight known A. salmonicida AHLs were also declined at high temperatures (above $16^{\circ} \mathrm{C}$ ) [9]. Additionally, we assume that changes in cell density may affect the gene expression involved in regulating phenotypes related to QS mechanism.

\section{Methods}

\section{Bacterial strains, culture conditions and supplements}

Bacterial strains used in this study are listed in Table 1. A. salmonicida LFI1238 strain and the constructed $A$. salmonicida mutants were grow on blood agar base no. 2 (Oxoid, Thermo Scientific) with a total concentration of $5 \%$ blood and $2.5 \% \mathrm{NaCl}$ (BA2.5) or in Luria Bertani broth (Difco, BD Diagnostics) with a total concentration of $2.5 \% \mathrm{NaCl}$ (LB2.5). A. salmonicida strains were cultivated from a single colony in $2 \mathrm{ml}(\mathrm{LB} 2.5)$ at $12^{\circ} \mathrm{C}, 220$ rpm for 2 days.
The GFP constitutive plasmid pVSV102, helper plasmid pEVS104 and suicide plasmid pNQ705 were propagated in Escherichia coli (E. coli), DH5 $\alpha \lambda$ pir, CC118 $\lambda$ pir and S17.1 $\lambda$ pir respectively. The E. coli strains were cultivated in $\mathrm{LB}$ or Luria Agar (LA) containing $1 \% \mathrm{NaCl}$ (LB1 and LA1 respectively) and incubated at $37^{\circ} \mathrm{C}$ and $220 \mathrm{rpm}$. The potential transconjugants were selected on BA2.5 supplemented with $2 \mu \mathrm{l} / \mathrm{ml}$ chloramphenicol or $150 \mu \mathrm{l} / \mathrm{ml}$ kanamycin.

A seawater-based medium (SWT) was used for the transcriptomics, biofilm and morphology assays. The medium consists of $5 \mathrm{~g} / \mathrm{L}$ of bacto peptone (BD Biosciences), $3 \mathrm{~g} / \mathrm{L}$ of yeast extract (Sigma-Aldrich) and $28 \mathrm{~g} / \mathrm{L}$ of a synthetic sea salt (Instant Ocean, Aquarium Systems).

\section{Transcriptomics}

Sample collection

Three biological replicates were used for all $A$. salmonicida strains. Cultures were grown from an individual

Table 1 Bacterial strains and plasmids used in this study

\begin{tabular}{|c|c|c|}
\hline Bacterial strains or plasmids & Description & Source \\
\hline \multicolumn{3}{|l|}{ A. salmonicida } \\
\hline LFI1238 & Wild-type, isolated from Atlantic cod & [36] \\
\hline$\Delta l i t R$ & LFI1238 containing an in-frame deletion in litR & [27] \\
\hline$\Delta r p o Q$ & LFI1238 containing an in-frame deletion in rpoQ & [33] \\
\hline$\Delta r p o Q-s y p Q^{-}$ & $\Delta r p o Q$ stain with an insertional disruption in sypQ, $\mathrm{Cm}^{r}$ & This study \\
\hline$\Delta r p o Q-s y p P^{-}$ & $\Delta r p o Q$ stain with an insertional disruption in syp, $\mathrm{Cm}^{r}$ & This study \\
\hline$\Delta r p o Q-s y p C^{-}$ & $\Delta r p o Q$ stain with an insertional disruption in sypC, $\mathrm{Cm}^{\mathrm{r}}$ & This study \\
\hline LFI1238-sypQ $Q^{-}$ & LFl1238 containing an insertional disruption in sypQ, $\mathrm{Cm}^{r}$ & This study \\
\hline LFI1238-syp $P^{-}$ & LFI1238 containing an insertional disruption in sypP, $\mathrm{Cm}^{r}$ & This study \\
\hline LFI1238-sypC & LFI1238 containing an insertional disruption in sypC, $\mathrm{Cm}^{r}$ & This study \\
\hline LFI1238- pVSV102 & A. salmonicida LFI1238 carrying pVSV102, $\mathrm{Kn}^{\mathrm{r}}$ & [33] \\
\hline$\Delta r p o Q-p V S V 102$ & $\Delta r p o Q$ carrying pVSV102, $\mathrm{Kn}^{\mathrm{r}}$ & [33] \\
\hline$\Delta r p o Q-s y p Q^{-}-p V S V 102$ & $\Delta r p o Q-s y p Q^{-}$carrying pVSV102, $\mathrm{Kn}^{\mathrm{r}}$ & This study \\
\hline$\Delta r p o Q-s y p P^{-}-p V S V 102$ & $\Delta r p o Q-s y p P^{-}$carrying pVSV102, $\mathrm{Kn}^{r}$ & This study \\
\hline$\Delta r p o Q-s y p C$-pVSV102 & $\Delta r p o Q-s y p C$ carrying pVSV102, $\mathrm{Kn}^{\mathrm{r}}$ & This study \\
\hline LFI1238-sypQ-pVSV102 & LFI1238-sypQ ${ }^{-}$carrying pVSV102, $\mathrm{Kn}^{\mathrm{r}}$ & This study \\
\hline LFI1238-syp $P^{-}$-pVSV102 & LFI1238-sypP $P^{-}$carrying pVSV102, $\mathrm{Kn}^{\mathrm{r}}$ & This study \\
\hline LFI1238-sypC -pVSV102 & LFI1238-sypC carrying pVSV102, $\mathrm{Kn}^{\mathrm{r}}$ & This study \\
\hline \multicolumn{3}{|l|}{ E. coli } \\
\hline C118入pir & Helper strain containing pEVS104 & [37] \\
\hline DH5a入pir & E. coli strain containing GFP plasmid pVSV102 & [37] \\
\hline \multicolumn{3}{|l|}{ Plasmids } \\
\hline pNQ705-sypQ $Q^{-}$ & pNQ705 containing an internal fragment of sypQ ${ }^{-}$ & [19] \\
\hline pNQ705-syp $P^{-}$ & pNQ705 containing an internal fragment of syp $P^{-}$ & [19] \\
\hline pNQ705-sypC & pNQ705 containing an internal fragment of $s y p C^{-}$ & [19] \\
\hline pVSV102 & pES213, constitutive GFP, $\mathrm{Kn}^{\mathrm{r}}$ & [37] \\
\hline pEVS104 & R6Korigin, RP4, oriT, trb tra and $\mathrm{Kn}^{\mathrm{r}}$ & [64] \\
\hline
\end{tabular}


colony in $2 \mathrm{ml} \mathrm{LB} 2.5$ medium at $12^{\circ} \mathrm{C}$ and $220 \mathrm{rpm}$ for 2 days. The 2 days culture was diluted 1:20 and grown overnight before being diluted to $\mathrm{OD}_{600}=0.05$ (optical density measured at $600 \mathrm{~nm}$ ) in a total volume of $70 \mathrm{ml} \mathrm{SWT}$ media supplemented with $2.5 \%$ sea salt. The cultures were grown further at $8^{\circ} \mathrm{C}$ and $220 \mathrm{rpm}$ in $250 \mathrm{ml}$ baffled flask. Samples $(10 \mathrm{ml})$ at low cell density $\mathrm{OD}_{600}=0.30$ and $(2.5$ $\mathrm{ml})$ at high cell density $\mathrm{OD}_{600}=1.20$ were harvested (13,000 x g, 2 min, $4^{\circ} \mathrm{C}$ ) (Heraeus $3 \mathrm{XR}$, Thermo Scientific). Samples were persevered in 5 th of their volume in RNAlater and stored at $-80^{\circ} \mathrm{C}$ until RNA extraction.

\section{Total RNA isolation and rRNA depletion}

The total RNA was extracted from the cell pellets following the standard protocols by manufactures (Masterpure DNA \& RNA purification kit, Epicenter). The quality of total RNA was determined using a Bioanalyzer and Total RNA nano chip (Agilent Technologies). The ribosomal rRNA was removed from the samples using Ribo-Zero rRNA Removal kit for bacteria (Illumina) following manufactures instructions. The quality of RNA after depletion was determined using Bioanalyzer and Total RNA pico chip (Agilent Technologies).

\section{RNA sequencing and data analysis}

The rRNA depleted samples were used to generate RNA-sequencing libraries using TruSeq strandard mRNA library prep kit (Illumina), and sequenced at the Norwegian Sequencing Center using the Illumina NextSeq 500 with mid output reagents with $75 \mathrm{bp}$ read length and paired end reads.

The sequencing quality of FASTQ files was assessed using FastQC. Further analysis of the RNA-Seq data was performed using a Galaxy pipeline consisting of EDGE-pro v1.0.1 [34] and DESeq2 [35]. EDGE-pro was used to align the reads to the $A$. salmonicida LFI1238 genome [36], and to estimate gene expression. Differences in gene expression between the reference genome of $A$. salmonicida wild-type and $\triangle l i t R$ and $\triangle r p o Q$ mutants were determined using DESeq2. Log2 fold changes of the genes were recalculated to $\times$ differential expression values (i.e., $\Delta l i t R / \mathrm{wt}$ ) and genes were defined as significantly differentially expressed genes (DEGs) based on a $p$-value $\leq 0.05$ and differentially expression values (fold change values) of $\geq 2 \times$ and $\leq-2 \times$ equal to $\log _{2}$ fold $\geq 1$ and $\leq-1$. tRNA and rRNA reads was filtered out before analysis.

The sequences from this study have been deposited in the European Nucleotide Archive (www.ebi.ac.uk/ena) under study accession number PRJEB28385.

\section{Construction of $A$. salmonicida LFI1238 and $\Delta r p o Q$ double mutants}

A. salmonicida harboring in-frame deletion in the rpoQ genes $(\triangle r p o Q)$ is described in our recent study [33]. The

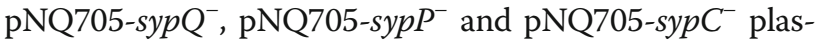
mids used to construct the mutants were described previously [19]. The LFI1238 and $\triangle r p o Q$ double mutants (Table 1) were constructed by transferring the pNQ705 plasmids carrying the targeted genes $(\operatorname{syp} Q$, syp $P$ and sypC) to LFI1238 wild-type or the $\Delta r p o Q$ mutant by bacterial conjugation. The conjugation of E. coli S17 $\lambda$ pir harboring different pNQ705 suicide constructs to recipient cells was done as described by others [19]. The resulting mutant strains were named LFI1238-syp $Q^{-}$, LFI1238-$\operatorname{sypP^{-}}$, LFI1238-syp $C^{-}, \Delta r p o Q-s y p Q^{-}, \Delta r p o Q-s y p P^{-}$and $\triangle$ rpoQ-sypC $C^{-}$.

\section{Construction of GFP tagged A. salmonicida strains}

The transfer of green fluorescence protein (GFP) into $A$. salmonicida was performed by tri-parental mating as described by others [37]. Briefly, the pVSV102 plasmid carrying the gene encoding for GFP and kanamycin was transferred from E. coli $\mathrm{DH} 5 \alpha$ to the mutant strains

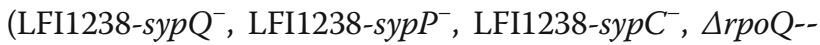
$\operatorname{syp} Q^{-}, \Delta r p o Q_{-}$syp $P^{-}$and $\left.\Delta r p o Q_{-}-s y p C^{-}\right)$using the conjugative helper strain CC118 $\lambda$ pir harboring pEVS104. Donor and helper cells were grown to mid-log phase $\left(\mathrm{OD}_{600}=\right.$ 0.7) in LB1. Recipient strains (A. salmonicida) were grown to early stationary phase $\left(\mathrm{OD}_{600}=1.2\right)$ in LB2.5. The donor, helper and recipient were harvested (13,000 x g, 1 min) and washed twice with LB1 before they were mixed in 1 to 1 ratio and spotted onto BA2.5 plates, followed by overnight incubation at $16^{\circ} \mathrm{C}$. The spotted cells were resuspended in LB2.5 and incubated for $24 \mathrm{~h}$ at $12^{\circ} \mathrm{C}$ with agitation $(220 \mathrm{rpm})$. The potential tagged strains were selected on BA2.5 after 5 days. The tagged strains were confirmed microscopically with Nikon Eclipse TS100.

\section{Static biofilm assay}

The biofilm assay was performed as described previously [19]. The overnight secondary cultures were grown to an $\mathrm{OD}_{600}$ of 1.3 in LB2.5. The secondary cultures were further diluted 1:10 in SWT and a total volume of $300 \mu \mathrm{l}$ was added to each well in flat-bottom, non-tissue culture-treated Falcon 24-well plates (BD, Bioscience). The plates were incubated statically at $8^{\circ} \mathrm{C}$, for $72 \mathrm{~h}$ and the biofilm was visualized using Nikon Eclipse TS100 microscope at 10x magnification and photographed with Nikon DS-5Mc.

\section{Colony morphology assay}

The colony morphology assay was performed as described previously $[19,33]$. The overnight secondary cultures were grown to an $\mathrm{OD}_{600}$ of 1.2 in LB2.5. From each secondary overnight culture, a $250 \mu \mathrm{l}$ was harvested by centrifugation, and the pellet was re-suspended in $250 \mu \mathrm{l}$ SWT. Then, $2 \mu \mathrm{l}$ of each culture was spotted onto SWT agar plates, and incubated at $8^{\circ} \mathrm{C}$ for 12 days. The colonies were viewed microscopically with Zeiss Primo 
Vert and photographed with AxioCam ERc5s at 4x magnification.

\section{Results}

Expression profiling of the $A$. salmonicida transcriptome The total assembled transcriptome of A. salmonicida wild-type LFI1238 generated an average of 9.87 million reads at $\mathrm{LCD}\left(\mathrm{OD}_{600}=0.3\right)$ and 9.56 million at $\mathrm{HCD}$ $\left(\mathrm{OD}_{600}=1.2\right)$. The average of mapped reads to the reference genome (A. salmonicida LFI1238) was $88.7 \%$ at LCD and $91.4 \%$ at HCD, with an average mapping coverage of 140.6 and 141.0 respectively, indicating that the transcriptome data were sufficient for further analysis (Additional file 1: Table S1). The detailed transcriptome data of $\triangle l i t R$ and $\triangle r p o Q$ are listed in Table S1 in the supplementary material (Additional file 1: Table S1).

\section{Cell density alters the expression pattern in $A$. salmonicida wild-type}

We identified one thousand and thirteen genes to be differentially expressed in a cell density dependent manner. The majority of DEGs (70\%) came from chromosome I, where the essential genes are located. The comparison (wt1.2/wt0.3) list of all DEGs are given in Table S2 in the supplementary material (Additional file 2: Table S2).

The comparison revealed that 597 (58.8\%) and 416 (41.0\%) of 1013 genes were significantly up- and downregulated, respectively. The 1013 DEGs were classified into different functional groups according to MultiFun [38]. Figure 1 shows a graphical presentation of the functional classes and the number of the differentially expressed genes of wild-type at HCD relative to LCD (wt1.2/wt0.3). A large number of significantly upregulated genes fell into cell envelop $(n=97,16.2 \%)$ where the genes with highest fold change values were VSAL_IIO321 (28.25 fold-change) and VSAL_IIO322 (28.74 fold-change) encoding for putative glycosyl transferase and membrane protein, respectively. Genes with unknown function were next largest functional group ( $n$ $=94,15.7 \%)$. Within this group, the highest fold change was observed in a number of genes coding for transposases. Among these were VSAL_IIO030 (1975.26-fold change), VSAL_I0514 (529.36-fold-change), VSAL_I1911 (237.06-fold change) and VSAL_1339 (129.70-fold change). Additionally a high fold change was also observed among genes coding for arginine/ornithine periplasmic binding protein (VASL_I1958, 32.83-fold change) and L-amino acid binding periplasmic protein (VSAL_I2057, 51.77-fold change) that fell into transport/binding proteins functional group ( $n=73,12.2 \%)$.

The comparison of wild-type transcriptome at HCD relative to LCD revealed an upregulation among genes known to be associated with AHL production. The luxI autoinducer synthase (VSAL_IIO957) responsible for the production of seven AHLs and its receptor luxR1

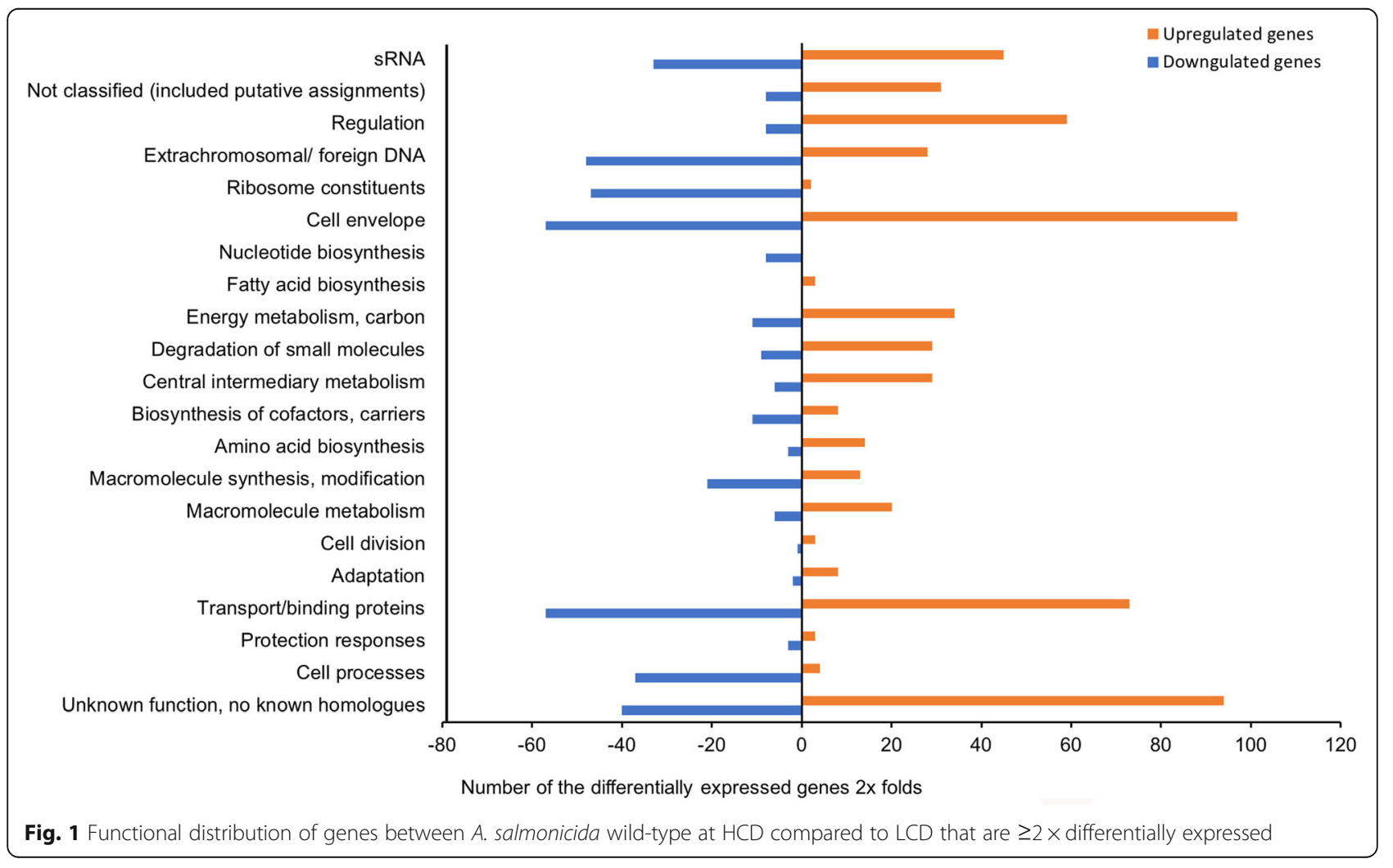


(VSAL_II0965) [9], were significantly differensially expressed with a fold change values of 3.72 and 3.23, respectively.

Fifty-nine (9.8\%) genes were classified into regulation functions, where we were able to identify the $r p o Q$ sigma factor (VSAL_IIO319) and 4 other genes from the same locus coding for putative response regulators (VSAL_IIO315, VSAL_IIO316, VSAL_IIO320, VSAL_IIO329). An additional 14 genes located close to $r p o Q$ or within the same operon were also highly upregulated in the wt 1.2 compared to wt 0.3 and fell into other functional groups such as cell envelope, extrachromosomal DNA and central intermediary metabolism, in addition to some hypothetical proteins with unknown or unclassified functions. litR, a transcription regulator of QS (VSAL_I2619), was also within the 59 upregulated genes involved in regulation with a fold change of 3.43 .

Even though the fatty acid and amino acid group showed only 3 upregulated genes, these genes exhibited high fold change values. VSAL_I2833 coding for acetyl-coenzyme A synthetase was among the highest with 290.53-fold change value. Other highly expressed genes were grouped in central metabolism such as VSAL_I2438 (57.86-fold change) and VSAL_I2439 (61.58-fold change) coding for isocitrate lyase and malate synthase A, respectively. Among the genes that fell into a group with not classified functions were genes coding for putative PrkA serine protein kinase
(VSAL_I2208, 56.64-fold change), putative anti-sigma F factor antagonist (VSAL_IIO328, 47.87-fold change), and putative nucleotidyltransferases (VSAL_ 2831, 38.11-fold change) (Fig. 1 and Additional file 2: Table S2). The remaining upregulated DEGs were grouped in other functional groups (Fig. 1 and Additional file 3: Table S3).

The majority of the downregulated genes fell into cell envelope and transport/ binding proteins with 57 significantly DEGs. Among the top 5 downregulated genes within transport/binding protein functional group were genes of the PTS system (VSAL_II0577, VSAL_IIO894, VSAL_IIO995 and VSAL_IIO966) with fold changes ranging from -44.43 to -8.34 (Additional file 3: Table S3).

Six genes (VSAL_IIO366, VSLA_IIO367, VSAL_IIO368, VSAL_IIO369, VSAL_IIO370 and VSAL_IIO373) located within the tight adherence (Tad) loci also known as tad operon were grouped in cell envelop and extrachromosomal DNA (subgroup pathogenicity island-related functions) functional groups. For all 6 genes the expression level ranging from -8.44 to -2.03 fold change at $\mathrm{HCD}$ (wt1.2) in comparison with that at LCD (wt0.3).

Thirty-six genes out of 37 genes that fell into cell processes were genes involved in cell motility and chemotaxis. Figure 2 shows the organization of the flagellar genes in the A. salmonicida genome, and Table 2 summarizes in detail the differentially expressed genes and operons. We were able to identify 28 genes coding for flagellar

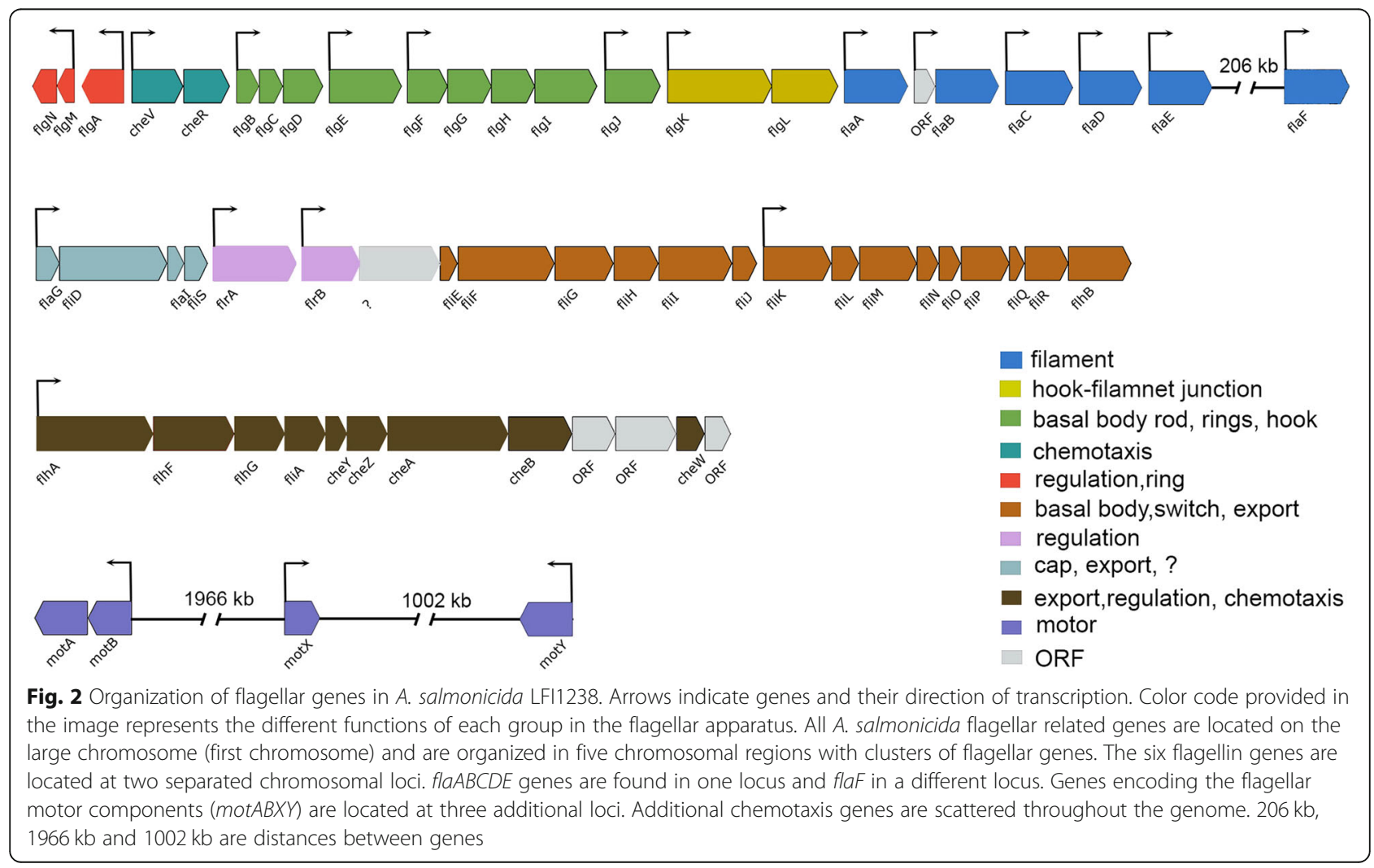


Table 2 Thirty-six differentially expressed genes involved in motility and chemotaxis in wt1.2/wt0.3

\begin{tabular}{|c|c|c|c|c|}
\hline VSAL_ID & FC & p-adjusted & Gene & Function \\
\hline VSAL_10799 & -2.55 & 3.1217E-13 & & methyl-accepting chemotaxis protein \\
\hline VSAL_11822 & -2.42 & $9.1448 \mathrm{E}-06$ & & methyl-accepting chemotaxis protein \\
\hline VSAL_11863 & -2.15 & $1.9114 \mathrm{E}-07$ & motY & sodium-type flagellar protein MotY precursor \\
\hline VSAL_12117 & -2.26 & 4.7375E-06 & & methyl-accepting chemotaxis protein \\
\hline VSAL_12193 & -2.96 & $1.4728 \mathrm{E}-16$ & & methyl-accepting chemotaxis protein \\
\hline VSAL_12293 & -2.18 & $9.8803 \mathrm{E}-11$ & $f l h A$ & polar flagellar assembly protein FlhA \\
\hline VSAL_12295 & -2.23 & $1.0662 \mathrm{E}-10$ & $f \mid h B$ & polar flagellar assembly protein FlhB \\
\hline VSAL_12298 & -2.17 & $2.498 \mathrm{E}-07$ & flip & polar flagellar assembly protein FliP \\
\hline VSAL_12299 & -2.18 & $9.0124 \mathrm{E}-10$ & fliO & polar flagellar assembly protein FliO \\
\hline VSAL_12300 & -2.11 & 3.8699E-09 & fliN & polar flagellar switch protein FliN \\
\hline VSAL_12301 & -2.02 & $2.1524 \mathrm{E}-08$ & flim & polar flagellar motor switch protein FliM \\
\hline VSAL_12302 & -2.27 & $1.8061 \mathrm{E}-10$ & flil & polar flagellar protein FliL \\
\hline VSAL_12303 & -2.05 & 9.5905E-09 & flik & polar flagellar hook-length control protein Flik \\
\hline VSAL_12304 & -2.15 & 1.6591E-06 & flij & polar flagellar assembly protein FliJ \\
\hline VSAL_12305 & -2.12 & $2.5798 \mathrm{E}-07$ & flil & polar flagellum-specific ATP synthase Flil \\
\hline VSAL_12306 & -2.66 & $2.9148 \mathrm{E}-17$ & $\mathrm{fliH}$ & polar flagellar assembly protein FliH \\
\hline VSAL_12307 & -2.61 & 5.6929E-15 & fliG & polar flagellar motor switch protein FliG \\
\hline VSAL_12308 & -2.73 & 7.0985E-17 & fliF & polar flagellar M-ring protein FliF (pseudogene) \\
\hline VSAL_12309 & -2.63 & 7.3748E-15 & flie & flagellar hook-basal body complex protein FliE \\
\hline VSAL_12313 & -2.13 & 4.8203E-13 & flis & polar flagellar protein FliS \\
\hline VSAL_12314 & -2.09 & $3.7432 \mathrm{E}-07$ & flal & polar flagellar protein Flal \\
\hline VSAL_12316 & -2.06 & $3.2548 \mathrm{E}-06$ & flaG & polar flagellar protein FlaG (pseudogene) \\
\hline VSAL_12319 & -2.68 & $1.6171 \mathrm{E}-16$ & flac & flagellin subunit $C$ \\
\hline VSAL_12327 & -2.20 & $1.314 \mathrm{E}-05$ & $f l a A$ & flagellin subunit A \\
\hline VSAL_12328 & -2.21 & $1.353 \mathrm{E}-08$ & $f l g L$ & flagellar hook-associated protein type $3 \mathrm{FlgL}$ \\
\hline VSAL_12329 & -2.33 & $3.2437 \mathrm{E}-10$ & flgk & hypothetical protein \\
\hline VSAL_12330 & -2.14 & 5.0777E-09 & $f l g J$ & peptidoglycan hydrolase FlgJ \\
\hline VSAL_12335 & -2.02 & 1.3131E-05 & $f l g E$ & flagellar hook protein FlgE \\
\hline VSAL_12336 & -2.13 & $1.3871 \mathrm{E}-10$ & $f \lg D$ & flagellar basal-body rod protein FlgD \\
\hline VSAL_12337 & -2.20 & 1.5834E-09 & $\mathrm{flgC}$ & flagellar basal-body rod protein FlgC \\
\hline VSAL_12338 & -2.29 & 8.8397E-09 & $f \lg B$ & flagellar basal-body rod protein FlgB \\
\hline VSAL_12517 & -2.51 & $3.4203 \mathrm{E}-14$ & flaF & flagellin subunit $F$ \\
\hline VSAL_12897 & -2.40 & $6.0326 \mathrm{E}-09$ & fliL & putative flagellar basal body-associated protein FliL \\
\hline VSAL_II0675 & -2.38 & 0.00023876 & & methyl-accepting chemotaxis protein \\
\hline VSAL_II0712 & -3.87 & 8.4405E-30 & & methyl-accepting chemotaxis citrate transducer \\
\hline VSAL_II1022 & -2.60 & 8.1567E-05 & & methyl-accepting chemotaxis protein \\
\hline
\end{tabular}

components (flagellin, flagellar basal body rod, rings, hook, cap proteins and flagellar assembly proteins), 7 genes coding for methyl-accepting chemotaxis protein and one gene coding for motor component, $\operatorname{mot} Y$.

The global comparison analysis of $A$. salmonicida wild-type at HCD compared to LCD resulted in an equal distribution of genes to be upregulated and downregulated. Additionally, the differentially expressed genes were distributed in all 21 functional classes (Fig. 1).
Expression profiles of $A$. salmonicida $\Delta r p o Q$ and $\Delta$ litR mutants compared to the wild-type at low and high cell densities

Expression profiling of $A$. salmonicida $\Delta$ litR mutant

As shown in Fig. 3, the transcriptome of $\Delta l i t R$ compared to the wild-type ( $\Delta l i t R / \mathrm{wt})$ resulted in a total of 62 DEGs at LCD, where half $(n=31,50.0 \%)$ was upregulated and the other half $(n=31,50.0 \%)$ was downregulated (Additional file 4: Table S4). At HCD we identified 


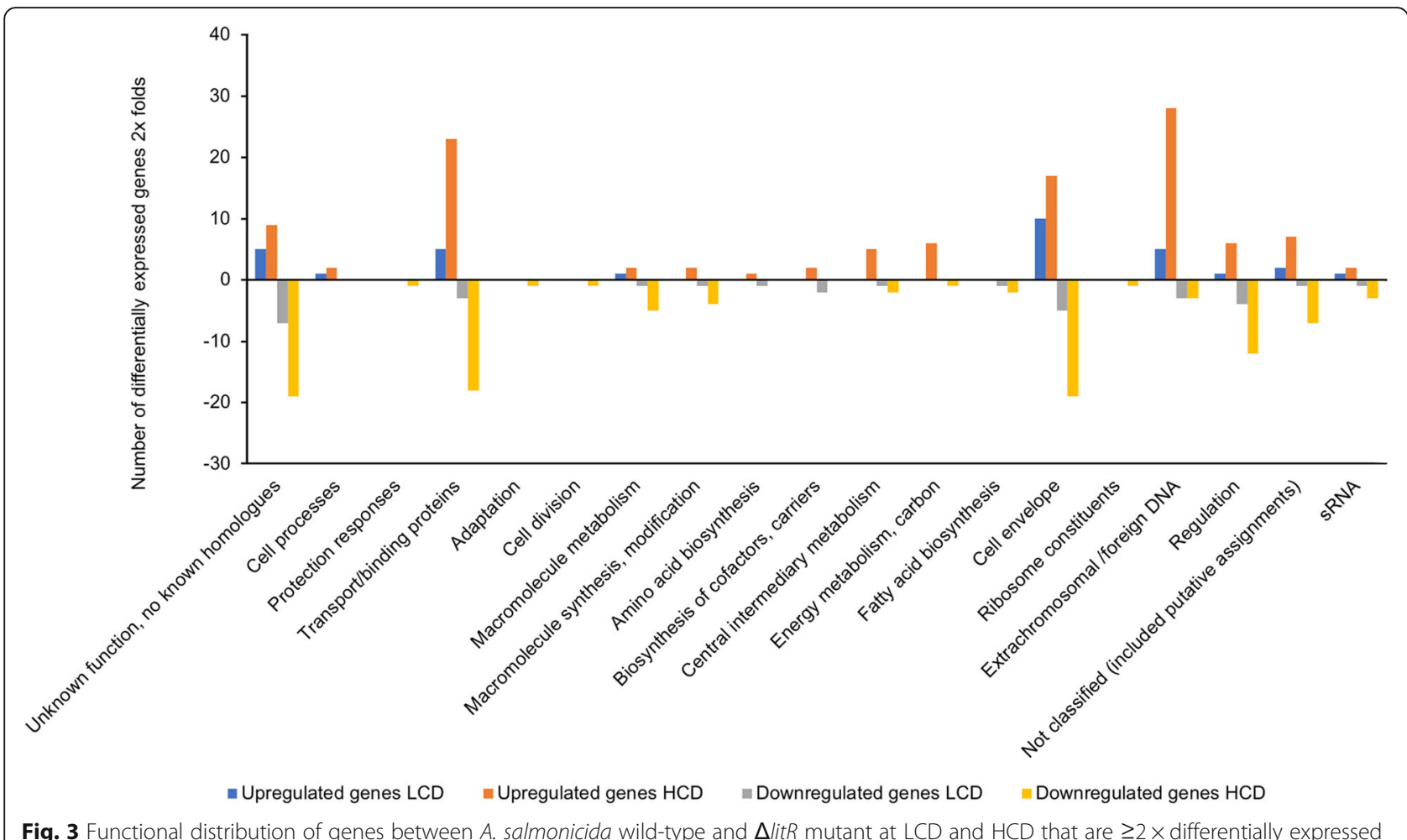

a total of 212 DEGs, 112 (53.9\%) upregulated and 100 (46.0\%) downregulated (Additional file 5: Table S5). The highest number of upregulated genes at LCD was represented in cell envelope with 10 genes (32.2\%), where 4 of them were genes associated with tad operon. Five genes (16.1\%) fell into each of extrachromosomal/foreign DNA, transport/binding proteins and genes of unknown functions. Other upregulated genes were involved in transport/binding proteins, cell processes mainly motility and chemotaxis, macromolecule metabolism, regulation and small RNA ( $s R N A$ ) (Additional file 6: Table S6). The highest number of downregulated genes fell into three major groups, unknown function ( $n=7,22.5 \%)$, cell envelope $(n=5,16.1 \%)$, and transport/binding proteins $(n=3$, 9.6\%). Four genes fell into the regulation functional group $(n=4,12.9 \%)$, where the rpoQ sigma factor (VSAL_IIO319) was among the significantly downregulated genes with -4.2 fold change value. The remaining downregulated genes were distributed in the other functional groups (Additional file 6: Table S6 and Fig. 3).

The 212 DEGs at HCD were distributed in 19 out of 21 functional classes (Fig. 3). The upregulated genes fell into 14 functional groups with highest number of genes in extrachromosomal/foreign DNA, transport/binding proteins and cell envelope groups with 28 (25\%), 23 (20.5\%) and 17 (15.1\%) genes respectively. The downregulated genes were distributed in fewer functional groups with highest number of genes in cell envelope $(n=19)$, unknown functions $(n=19)$, transport/ binding proteins $(n=18)$, and regulation $(n=12)$. Other downregulated genes fell into other functional categories and range from 1 to 7 genes out of 100 downregulated genes (Additional file 6: Table S7).

In summary, the transcriptome of $\Delta l i t R$ relative to the wild-type exhibited an equal gene distribution between upregulated and downregulated genes which suggests that LitR may act both as a positive and negative regulator in A. salmonicida.

\section{Expression profiling of A. salmonicida $\triangle r p o Q$ mutant}

Figure 4, represents the transcriptome of $\triangle r p o Q$ relative to the wild-type $(\triangle r p o Q / w t)$ at LCD and HCD. The LCD transcrimtome resulted in a total of 84 DEGs, where 43 $(51.2 \%)$ were upregulated and 41 (48.8\%) were downregulated (Additional file 7: Table S8). At HCD we identified in total 300 DEGs, 206 (68.6\%) upregulated and 94 (31.3\%) downregulated (Additional file 8: Table S9). The 84 DEGs at LCD were distributed into 8 functional groups (Fig. 4). Among the 43 upregulated genes (LCD), 18 genes $(41.8 \%)$ were grouped within the cell envelope group, where VSAL_IIO252 annotated as hypothetical protein was among the genes with high fold change value (16.1-fold change). Nine genes (20.9\%) fell into each of unknown functions and extrachromosomal/foreign DNA. Three genes (6.9\%) were allocated to regulation and one gene (VSAL_IIO170) codes for 


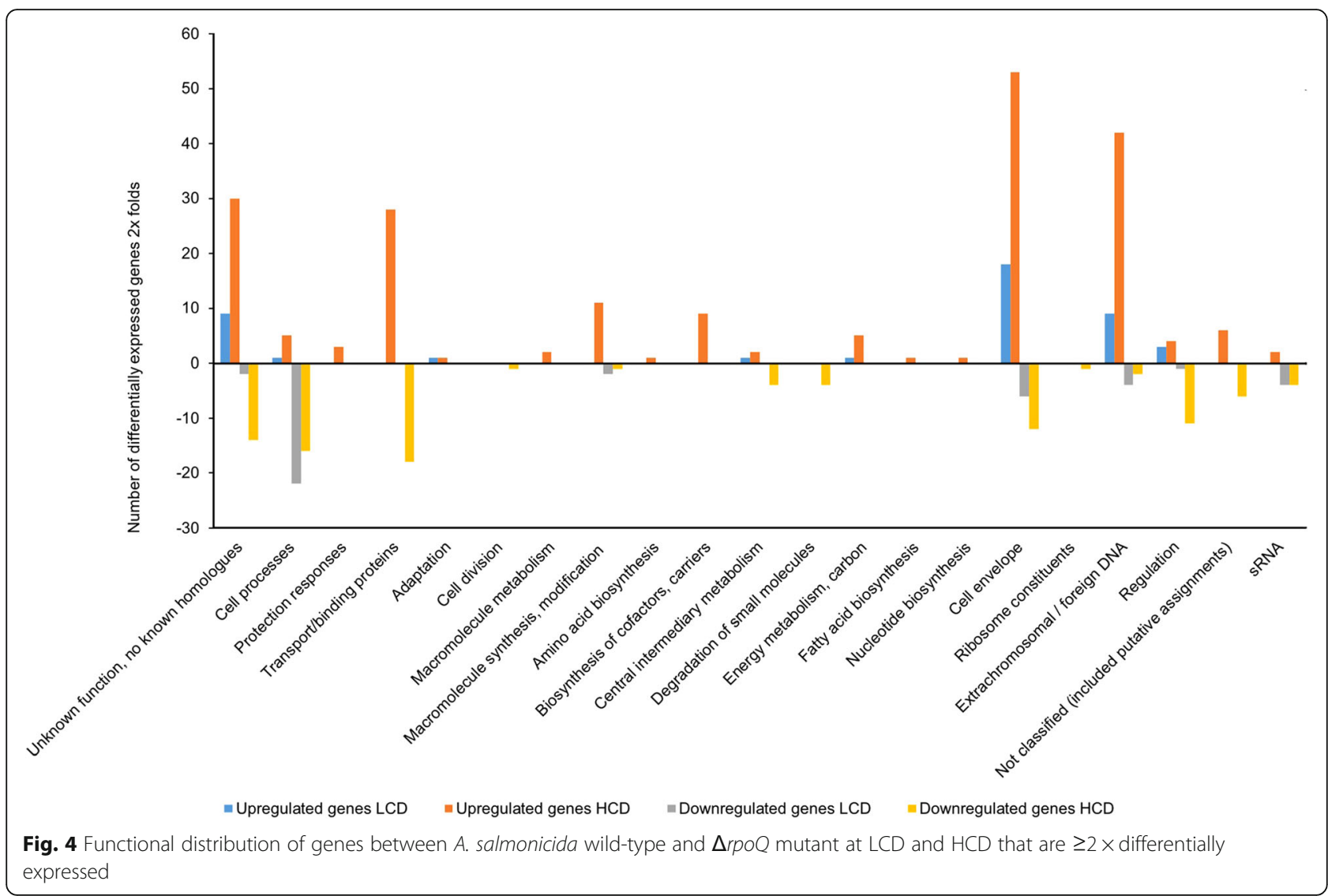

methyl-accepting chemotaxis protein was grouped in cell processes (Additional file 9: Table S10). The 41 downregulated genes were distributed in 7 functional groups with highest number of genes within cell processes $(n=22$, 53.6\%). Other downregulated genes fell into cell envelope $(n=6,14.6 \%), \quad s R N A$ and extrachromosomal/foreign DNA with 4 genes $(9.7 \%)$ in each group and unknown functions with 2 hypothetical genes VSAL_I2061 and VSAL_II1023.

Figure 4 shows the 300 DEGs at HCD and their distribution among the 21 functional groups. Among the 206 $(68.8 \%)$ upregulated genes, $53(25.7 \%)$ genes were involved in cell envelope, 42 (20\%) in extrachromosomal/ foreign DNA and 30 (14.5\%) hypothetical genes with unknown functions (Additional file 9: Table S11). The remaining upregulated genes were distributed among other functional groups with a percentage ranging from 13.5 to $0.4 \%$ (Additional file 9: Table S11). The 94 downregulated genes at $\mathrm{HCD}$ were mostly represented in transport/binding proteins $(n=18,19 \%)$, cell processes $(n$ $=16,17 \%)$, hypothetical proteins with unknown functions $(n=14,14.8 \%)$, cell envelope $(n=12,12.7 \%)$ and genes involved in regulation $(n=11,11.7 \%)$. The remaining genes fell into other functional categories and ranging from 1 to 6 genes out of 94 downregulated genes (Additional file 9: Table S11).
The transcriptome of $\triangle r p o Q$ compared to the wild-type, showed more upregulated genes $(68.8 \%)$, than downregulated (31.2\%) at HCD, which indicates that RpoQ acts more as a negative regulator in $A$. salmonicida at high cell density.

\section{Deletion of litR and rpoQ impacts operons related to quorum sensing}

A large number of genes that fell in the cell processes functional group in both $\triangle l i t R$ and $\triangle r p o Q$ were genes involved in the signaling cascade of bacterial chemotaxis and flagellar biosynthesis. Transcriptional analysis of $\triangle r p o Q$ compared to the wild-type revealed 29 genes that were considerably downregulated at both low and high cell densities. Among the genes that had the greatest transcript abundance at LCD was the gene encoding flagellin A protein, flaA (-61.99-fold change). Other flagellin genes were either expressed with lower fold change values such as $f l a B$ (-2.05-fold change), flaC (-6.29-fold change) and flaE (-2.70-fold change) or filtered out due to the predetermined criteria for identifying DEGs (fold change value $\geq 2$ and $\leq-2, p$-value $\leq 0.05$ ) such as, flaD (-1.98-fold change) and flaF (-1.8-fold change). In addition to the genes coding for flagellin proteins, genes coding for flagellar basal body rod, ring, hook and cap proteins (fliD, flaG, flgB-flgL) showed also reduced level 
of expression compared to control (wild-type) (Additional file 7: Table S8). Likewise, at HCD 12 out of 16 downregulated genes grouped in cell processes were flagellar genes. In particular, the expression of flaA was highly decreased with a fold change value of -17.36 . The remaining flagellin genes were expressed at a lower level as $f l a C$ (-2.04-fold change), while others such as $f l a B$ (-1.4-fold change), flaD (-1.4-fold change), flaE (-1.6-fold change) and flaF (1.17- fold change), were filtered out due to a fold change values below $\leq 2$ and $\geq-2$. Genes encoding flagellar basal body rod, ring and hook proteins (from $f \lg B$ to $f \lg L$ ) were also downregulated with fold change values ranging from -3.53 to -11.69 . In addition to the flagellar genes, 4 genes encoding methyl-accepting chemotaxis proteins were also downregulated such as VSAL_I2193, VSAL_IO799 at LCD, VSAL_I0712 at HCD and VSAL_II1022 at both low and high cell densities (Additional file 8: Table S9).

In contrast to $\triangle r p o Q$ transcriptome $(\Delta r p o Q / w t)$, the $\Delta l i t R$ transcription profiling ( $\Delta l i t R / \mathrm{wt})$ exhibited an increased level of expression among genes involved in cell motility and chemotaxis. One gene, VSAL_I2117, encoding methyl-chemotaxis accepting proteins was upregulated with fold change values of 3.84 and 3.46 at low and high cell densities, respectively. Only one flagellin gene, flaC gene (VSAL_I2317) was found to be upregulated with a fold change of 2.64 at HCD (Additional file 5: Table S5).

The second most highly expressed group of genes are those associated with the tad operon. The tad operon in A. salmonicida consists of 13 genes (VSAL_IIO366 to VSAL_IIO378) and is located on the second chromosome, that harbours accessory genes [36] (Fig. 5).
The transcriptome of $\triangle r p o Q(\Delta r p o Q / w t)$ at LCD showed that all $13 \mathrm{tad}$ genes were highly upregulated (Table 3). Nine tad genes (VSAL_IIO369, VSAL_IIO371, VSAL_IIO372,VSAL_IIO373,VSAL_II0374,VSAL_II375, VSAL_IIO376, VSAL_IIO377 and VSAL_IIO378) were classified as pathogenicity island-related factors. The other 5 tad genes (VSAL_IIO366, VSAL_IIO367 and VSAL_IIO368) fell into surface structures group coding for Flp-type pilus protein. At HCD 8 out of 13 genes exhibiting an increased level of expression based on our criteria (fold change value $\geq 2$ and $\leq-2, p$-value $\leq 0.05$ ). Four tad genes were classified within pathogenicity island-related functions (VSAL_IIO369, VSAL_IIO371, VSAL_IIO372 and VSAL_IIO373), other 4 were divided into surface structures (VSAL_IIO366, VSAL_IIO367, VSAL_IIO368) and membrane exported lipoproteins (VSAL_IIO370). All 8 tad DEGs ranged from 11.09 to 5.6-fold change (Table 3).

In comparison to $\triangle r p o Q$, the $\Delta l i t R$ transcriptome relative to the wild-type revealed fewer tad genes to be differentially expressed in our analysis. An equal number of differentially expressed genes was present in both LCD and HCD with approximately similar fold change values (Table 3).

Exopolysaccharide genes are highly expressed in the $\Delta$ litR and $\triangle r p o Q$ mutants

The inactivation of either rpoQ or litR in A. salmonicida resulted in strains with enhanced extracellular polysaccharide production, which is involved in biofilm formation and wrinkled colony morphology $[19,33]$. The biosynthesis of EPS in A. salmonicida likely requires the expression of syp operon (22,453 bp) located on the second chromosome [36]. The syp operon consists of 18

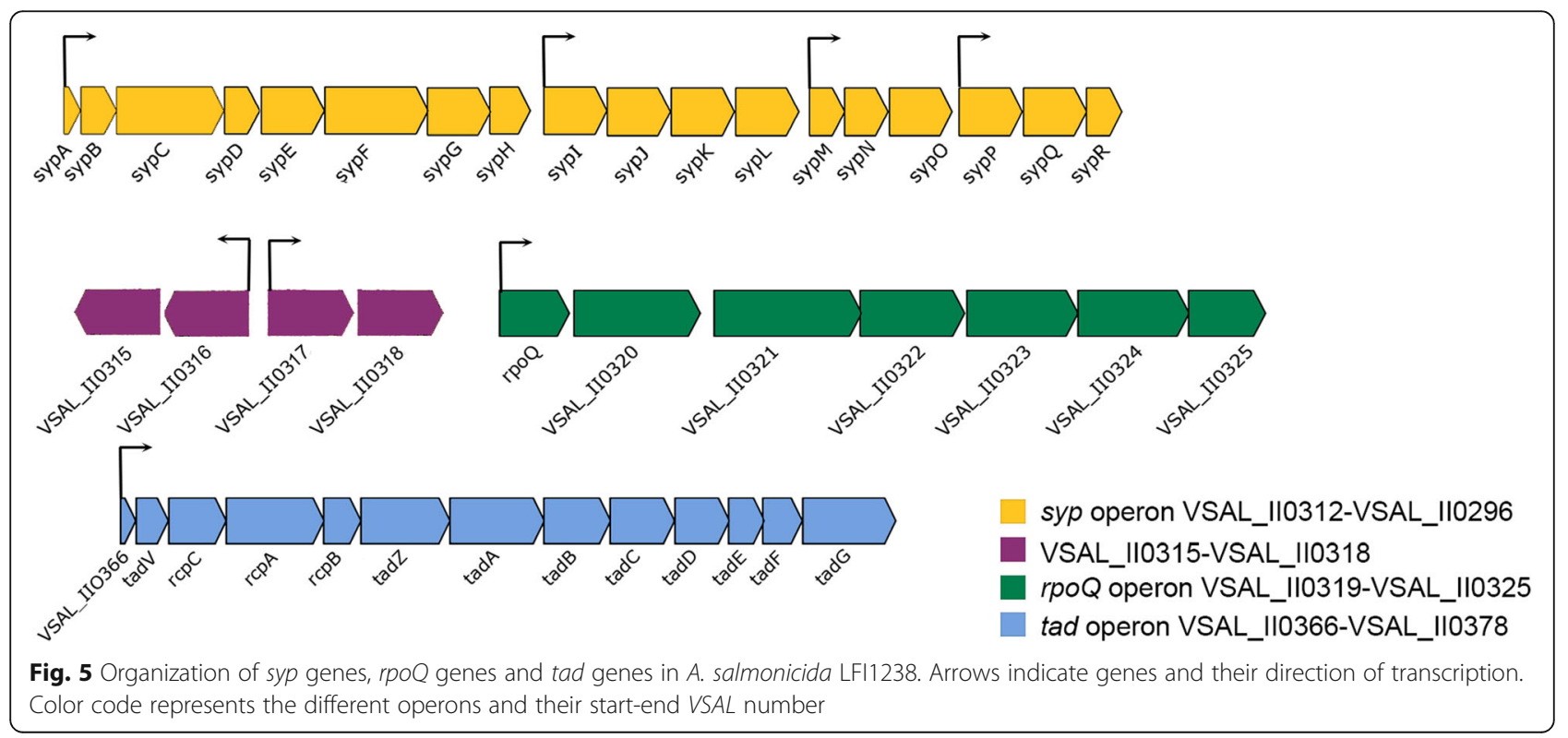


Table 3 Genes of the tad operon of $\Delta /$ itR/wt and $\Delta r p o Q / w t$ at low and high cell densities

\begin{tabular}{|c|c|c|c|c|c|c|}
\hline \multirow[t]{2}{*}{ VSAL_ID } & \multicolumn{2}{|l|}{ LCD } & \multicolumn{2}{|l|}{$\mathrm{HCD}$} & \multirow[t]{2}{*}{ Gene } & \multirow[t]{2}{*}{ Function } \\
\hline & $\overline{F C}$ & p-adjusted & $\mathrm{FC}$ & p-adjusted & & \\
\hline \multicolumn{7}{|l|}{$\Delta r p o Q / w t$} \\
\hline VSAL_II0366 & 25.55 & $1.58 \mathrm{E}-95$ & 11.88 & 1.16E-09 & & fimbrial protein, Flp/Fap pilin component \\
\hline VSAL_II0367 & 24.82 & 7.13E-119 & 10.45 & 8.51E-10 & $\operatorname{tad} V$ & type IV leader peptidase \\
\hline VSAL_II0368 & 14.23 & $1.86 \mathrm{E}-123$ & 6.78 & $3.37 \mathrm{E}-14$ & $r c p C$ & putative Flp pilus assembly protein \\
\hline VSAL_II0369 & 10.94 & 5.17E-98 & 7.24 & 4.39E-16 & rсpA & type I/III secretion system protein \\
\hline VSAL_II0370 & 14.26 & $3.98 \mathrm{E}-113$ & 7.42 & $5.14 \mathrm{E}-10$ & $r c p B$ & putative lipoprotein \\
\hline VSAL_II0371 & 13.54 & $2.15 \mathrm{E}-108$ & 6.16 & NA & $\operatorname{tad} Z$ & type II secretion system protein Z \\
\hline VSAL_II0372 & 12.73 & $6.04 \mathrm{E}-118$ & 5.63 & $1.76 \mathrm{E}-07$ & $\operatorname{tad} A$ & type II/IV secretion system protein, ATP binding domain \\
\hline VSAL_II0373 & 10.33 & $1.16 \mathrm{E}-86$ & 6.99 & 4.54E-16 & $\operatorname{tad} B$ & bacterial type II secretion system protein F \\
\hline VSAL_II0374 & 4.65 & $9.46 \mathrm{E}-64$ & 1.49 & $5.18 \mathrm{E}-01$ & $\operatorname{tad}$ & bacterial type II secretion system protein F \\
\hline VSAL_II0375 & 2.94 & $1.16 \mathrm{E}-29$ & 1.18 & 7.92E-01 & $\operatorname{tad} D$ & putative secretion system protein \\
\hline VSAL_II0376 & 3.17 & $1.38 \mathrm{E}-31$ & 1.16 & $8.00 \mathrm{E}-01$ & tadE & membrane associated secretion system protein \\
\hline VSAL_II0377 & 3.11 & 9.37E-30 & 1.06 & $9.18 \mathrm{E}-01$ & tadF & membrane associated secretion system protein \\
\hline VSAL_II0378 & 3.04 & $1.68 \mathrm{E}-30$ & 1.11 & $8.50 \mathrm{E}-01$ & $\operatorname{tad} G$ & membrane associated secretion system protein \\
\hline \multicolumn{7}{|l|}{$\Delta / i t R / w t$} \\
\hline VSAL_II0366 & 12.23 & 7.54E-75 & 10.24 & $2.94 \mathrm{E}-13$ & & fimbrial protein, Flp/Fap pilin component \\
\hline VSAL_II0367 & 8.59 & $3.94 \mathrm{E}-59$ & 6.44 & $1.20 \mathrm{E}-12$ & $\operatorname{tadV}$ & type IV leader peptidase \\
\hline VSAL_II0368 & 4.30 & 1.07E-38 & 2.42 & NA & $r c p C$ & putative Flp pilus assembly protein \\
\hline VSAL_II0369 & 3.45 & $4.58 \mathrm{E}-30$ & 3.10 & $6.14 \mathrm{E}-05$ & rcpA & type $\|/ /\|$ secretion system protein \\
\hline VSAL_II0370 & 4.67 & 1.77E-37 & 2.74 & 0.009798979 & $r c p B$ & putative lipoprotein \\
\hline VSAL_II0371 & 3.73 & $1.31 \mathrm{E}-24$ & 2.38 & 0.004220895 & $\operatorname{tad} Z$ & type II secretion system protein Z \\
\hline VSAL_II0372 & 3.67 & $2.53 \mathrm{E}-27$ & 2.43 & 0.000108788 & $\operatorname{tad} A$ & type II/IV secretion system protein, ATP binding domain \\
\hline VSAL_II0373 & 2.49 & $1.89 \mathrm{E}-11$ & 2.53 & NA & $\operatorname{tad} B$ & bacterial type II secretion system protein F \\
\hline VSAL_II0374 & 1.88 & $7.21 \mathrm{E}-09$ & 1.06 & 0.926675356 & $\operatorname{tad} C$ & bacterial type II secretion system protein F \\
\hline VSAL_II0375 & 1.32 & 0.031001079 & 1.29 & 0.372370396 & $\operatorname{tad} D$ & putative secretion system protein \\
\hline VSAL_II0376 & 1.45 & 0.001283239 & 1.29 & 0.376863481 & tadE & membrane associated secretion system protein \\
\hline VSAL_II0377 & 1.53 & 0.000365049 & 1.35 & 0.33429395 & tadF & membrane associated secretion system protein \\
\hline VSAL_II0378 & 1.35 & 0.006750764 & 1.35 & 0.304804669 & $\operatorname{tad} G$ & membrane associated secretion system protein \\
\hline
\end{tabular}

Values indicated in bold are differentially expressed genes with fold change values (FC) that are $\geq 2$ and $\leq-2, p$-value $\leq 0.05$

genes (VSAL_IIO295 to VSAL_IIO312) organized into four transcription units (Fig. 5).

The transcriptome of $\Delta r p o Q$ compared to the wild-type, showed that 13 syp genes were upregulated at HCD, whereas at LCD only $\operatorname{sypB}$ (VSAL_IIO311) was differentially expressed with a fold change value of 2.03 (Table 4).

Next, we wanted to analyze the importance of syp genes in formation of colony rugosity and biofilm and for this 3 syp genes $(\operatorname{syp} Q, \operatorname{syp} P$ and $\operatorname{syp} C)$ were separately inactivated in the wild-type LFI1238 and $\triangle r p o Q$ mutant by insertional inactivation. The constructed mutants were GFP tagged for better biofilm visualization. The inactivation of $\operatorname{syp} Q, P$ or $C$ in $\triangle r p o Q$ resulted in strains similar to the wild-type strain with no biofilm formation and smooth colonies (Additional file 10: Figure S1). No difference was observed on biofilm formation or colony morphology after the inactivation of syp genes in A. salmonicida wild-type at the chosen conditions (Additional file 10: Figure S1).

The transcriptome of $\Delta l i t R(\Delta l i t R / w t)$ did not show any significant upregulation of the syp genes, except for two genes; sypA (VSAL_IIO312) and sypC (VSAL_IIO310) encoding a putative anti-sigma factor and polysaccharide biosynthesis/export protein, respectively (Additional file 5: Table S5). Our results indicate that this operon is regulated in a cell density dependent manner, where RpoQ expression leads to a repression of large number of syp genes at HCD.

\section{Comparative analysis of $\triangle r p o Q$ and $\Delta l i t R$ reveals genes regulated by QS}

RpoQ and LitR were studied previously and shown to regulate phenotypes such as motility, adhesion, biofilm 
Table 4 DEGs of syp locus at low and high cell densities in the $\Delta r p o Q / w t$

\begin{tabular}{|c|c|c|c|c|c|c|}
\hline \multirow[t]{2}{*}{ VSAL_ID } & \multicolumn{2}{|l|}{ LCD } & \multicolumn{2}{|l|}{$\mathrm{HCD}$} & \multirow[t]{2}{*}{ Gene } & \multirow[t]{2}{*}{ Function } \\
\hline & $\overline{F C}$ & $\overline{p \text {-adjusted }}$ & $\overline{F C}$ & $\overline{p \text {-adjusted }}$ & & \\
\hline VSAL_II0295 & 1.22 & 0.74710921 & 2.189 & 0.07468146 & $\operatorname{sypR}$ & sugar transferase \\
\hline VSAL_II0296 & 1.07 & 0.89636775 & 2.585 & 0.00426114 & $\operatorname{syp} Q$ & putative transmembrane glycosyl transferase \\
\hline VSAL_II0297 & 1.10 & 0.84634234 & 3.182 & 0.0001044 & syp $P$ & putative glycosyl transferase \\
\hline VSAL_II0298 & -1.05 & 0.91873517 & 2.462 & 0.04236082 & sypo & putative membrane protein \\
\hline VSAL_II0299 & 1.14 & 0.81791828 & 2.189 & 0.11185209 & $\operatorname{syp} N$ & putative glycosyl transferases \\
\hline VSAL_II0300 & 1.43 & 0.17621734 & 3.160 & 0.00642603 & sypm & hypothetical protein \\
\hline VSAL_II0301 & -1.25 & 0.56460157 & 1.778 & 0.44063722 & sypl & O-antigen polymerase \\
\hline VSAL_II0302 & 1.12 & 0.85566635 & 2.713 & 0.04069669 & sypk & putative polysaccharide biosynthesis protein \\
\hline VSAL_II0303 & 1.10 & 0.87199934 & 2.928 & 0.00991193 & syp」 & putative glycosyl transferase \\
\hline VSAL_II0304 & 1.23 & 0.60244622 & 2.868 & 0.00187435 & sypl & putative glycosyl transferase \\
\hline VSAL_II0305 & -1.23 & 0.602336 & 1.035 & 0.96181635 & sypH & putative glycosyl transferase \\
\hline VSAL_II0306 & -1.35 & 0.2022748 & -1.647 & 0.06439411 & $\operatorname{syp} G$ & $\begin{array}{l}\text { two-component response regulator, transcriptional } \\
\text { regulatory protein LuXO }\end{array}$ \\
\hline VSAL_II0307 & -1.17 & 0.69188251 & -1.157 & 0.76925525 & sypF & response regulator, histidine kinase \\
\hline VSAL_II0308 & 1.25 & 0.4506543 & 1.021 & 0.97005546 & sype & putative response regulator \\
\hline VSAL_II0309 & 1.20 & 0.73767376 & 2.189 & 0.08945561 & sypD & putative capsular polysaccharide synthesis protein \\
\hline VSAL_II0310 & 1.49 & 0.08145483 & 3.811 & 0.00016578 & $\operatorname{syp} C$ & polysaccharide biosynthesis/export protein \\
\hline VSAL_II0311 & 2.03 & 0.00119744 & 4.377 & 0.00012723 & syp $B$ & outer membrane protein, OmpA family \\
\hline VSAL_II0312 & 1.94 & 0.01339391 & 6.063 & 5.41E-06 & sypA & $\begin{array}{l}\text { hypothetical protein, putative anti-sigma } \\
\text { factor antagonist }\end{array}$ \\
\hline
\end{tabular}

Values indicated in bold are differentially expressed genes with fold change values (FC) that are $\geq 2$ and $\leq-2, p$-value $\leq 0.05$

formation and colony morphology differently in A. salmonicida [19, 33]. To identify genes that are differentially expressed in $\triangle r p o Q$ relative to $\Delta l i t R$, we compared the RNA-Seq data for these mutants at low and high cell densities using DESeq. At LCD a differential expression analysis revealed $63(53.3 \%)$ and $55(46.6 \%)$ of the total 118 genes to be significantly up and downregulated respectively (Additional file 11: Table S12). Whereas at
HCD the RNA-Seq revealed 107 genes where 55 (51.4\%) were upregulated while $57(53.2 \%)$ were downregulated. Figure 6 illustrates the number of DEGs that overlap between the $\triangle r p o Q$ and $\triangle l i t R$ transcriptome where the majority of the differentially expressed genes at both cell densities came from chromosome I. At both low and high cell densities, genes associated with several phenotypes known to be related to QS were significantly

\section{A}

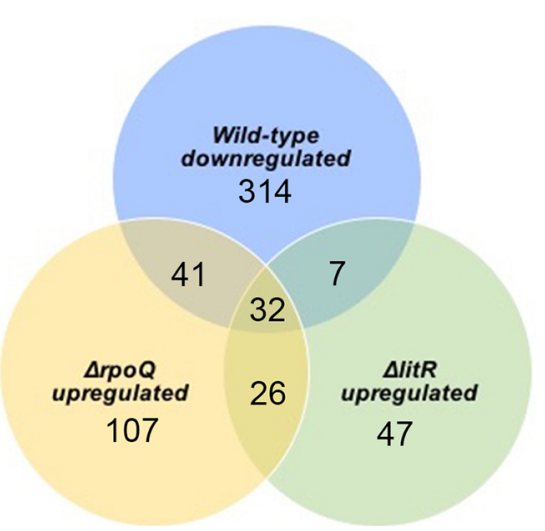

B

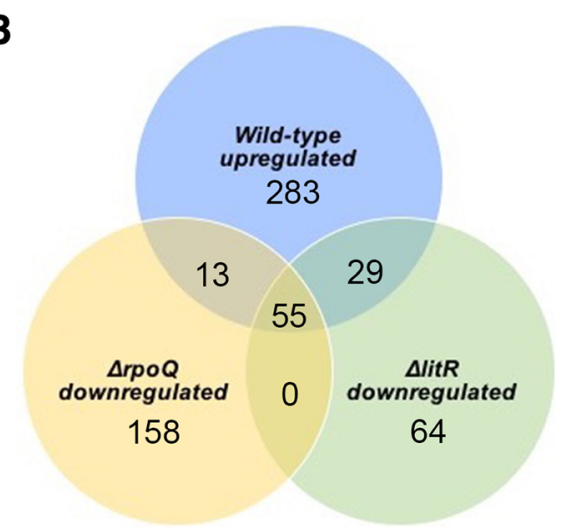

Fig. 6 Venn diagram of differentially expressed genes a) Venn diagram of upregulated genes in the $\Delta$ litR and $\Delta$ rpoQ mutants and downregulated genes in the wild-type at HCD. b) Venn diagram of downregulated genes in the $\Delta$ litR and $\Delta r p o Q$ mutants and upregulated genes in the wild-type at HCD. The sum of the numbers in each large circle represents total number of uniquely differentially expressed genes identified in each sample. The overlap part of the circles represents number of overlapping differentially expressed genes between combinations 
expressed in the $\triangle r p o Q$ relative to $\Delta$ litR. Among these were genes involved in motility and chemotaxis, genes associated with the syp operon such as (VSAL_IIO297) encoding a putative glycosyl transferase, (VSAL_IIO300) annotated as hypothetical protein, (VASL_IIO311) coding for the outer membrane protein OmpA and (VSAL_IIO312) coding for a putative anti-sigma factor, in addition to some genes associated with the tad operon (Additional file 11: Table S12 and Additional file 12: Table S13).

\section{Discussion}

Whole-transcriptome RNA sequencing analysis provides a powerful understanding of the gene expression patterns underlying the basic biology of the organism. In this work we studied the comparative transcriptome of A. salmonicida LFI1238, $\Delta l i t R$ and $\triangle r p o Q$ mutants at low $\left(\mathrm{OD}_{600}=0.3\right)$ and high $\left(\mathrm{OD}_{600}=1.2\right)$ cell densities in SWT medium at $8^{\circ} \mathrm{C}$. The SWT medium $(2.5 \%$ salt concentration) and low temperature $\left(8^{\circ} \mathrm{C}\right)$ were chosen as appropriated physiological conditions (similar to ocean environment) for $A$. salmonicida which is responsible for developing of cold-water vibriosis in Atlantic salmon at low seawater temperatures [39-41]. These conditions also favoured the development of several phenotypes (as motility, morphology and biofilm) related to QS in our $\triangle l i t R$ and $\triangle r p o Q$ mutants in vitro $[19,33]$. The differentially expressed genes identified in this work provide a new insight to explain mechanisms related to QS such as motility, bioluminescence, wrinkled colony morphology, adhesiveness and biofilm formation.

\section{Changes in cell density impacts genes related to quorum sensing in A. salmonicida LFI1238}

QS is known to be a cell density dependent mechanism allowing communication between bacteria and is regulated through master regulators, as VanT, HapR and LitR $[28,42,43]$. LitR was shown previously to regulate cryptic bioluminescence in A. salmonicida, where its inactivation resulted in less light production [44]. This led us to propose that cryptic bioluminescence is a high cell density dependen phenotype, where LitR is involved in its regulation. Herein, the transcriptome of A. salmonicida at HCD showed a significant upregulation of lux operon (Additional file 2: Table S2), confirming that the alteration in gene experession of this operon is affected by changes in population.

RpoS sigma factor aids in adaptation to environmental stress, mainly required for virulence, stress resistance and biofilm formation, additionally it has been shown to be required for full motility in some vibrios [45]. In this study rpoQ (RpoS-like sigma factor) was found to be upregulated in A. salmonicida at HCD compared to LCD. Moreover, the transcriptome of A. salmonicida demonstrated a downregulation in genes associated with motility and chemotaxis. This explains our previously obtained results, where the overexpression of RpoQ in the wild-type resulted in non-motile strains [33]. Hence, the expression of rpoQ leads to reduced motility in $A$. salmonicida at HCD. So why do A. salmonicida reduce their motility at HCD? It is believed that bacteria have different expression profiles during the different stages of life cycle. However, a complete life cycle of A. salmonicida is still unknown. But we assume that $A$. salmonicida similar to $V$. cholerae, is able to change from planktonic to biofilm life cycle which results in changes in genes expression required for motility and other functions $[46,47]$. The high cell density transcriptome presented in this study exhibits the activities of the late exponential phase $\left(\mathrm{OD}_{600}=1.2\right)$. During this phase nutrition accessibility is limited which favors the bacterial cells to enter the stationary phase and QS. Thus, at this time period the accumulation of autoinducers results in the expression of LitR, which in turn activates the rpoQ expression leading to activate regulators responsible for motility reduction, hence protecting the bacteria from excessive energy loss required to manage the motility apparatus. Additionally, it has been shown that A. salmonicida suppresses motility under the late stages of the host colonization (i.e., $\mathrm{HCD}$ ) $[48,49]$. In contrast to HCD, at LCD we believe that the expression of motility genes in A. salmonicida are upregulated resulting in motile strains able to swim and colonize new host or environment. However the mechanism by which flagellar biosynthesis is controlled in A. salmonicida seems to be complex and will require further studies.

\section{LitR and RpoQ regulate genes vital for motility}

A. salmonicida is motile by nine polar flagella [50], where genes required for flagellum biosynthesis and flagellar motility are organized in different loci (Fig. 2) in a similar manner to A. fischeri [49]. The expression of genes involved in the synthesis of flagella in vibrios is tightly regulated through a complex hierarchy requiring the presence of regulatory proteins and the production of the flagellin monomer the basic component of bacterial flagellum, such as, FlaA [10, 51]. RpoQ was shown to be a positive regulator of motility in $A$. salmonicida under our experimental conditions [33], and here we determine that the deletion of rpoQ resulted in a downregulation of several flagellar and chemotaxis genes, mainly flaA at both cell densities. Although A. salmonicida flagellar filament is composed of six flagellins (Fig. 2), it appears that the FlaA protein is mainly essential for motility and most likley regulated by RpoQ. The importance of FlaA for motility was reported in $V$. cholerae, where its deletion affected motility and thereby virulence [44]. Similarly, in A. fischeri the inactivation of flaA 
resulted in strains with reduced motility and symbiotic competence [52]. Likewise, a considerable importance of FlaA for motility was recently documented in A. salmonicida LFI1238, where the complete deletion of flaA resulted in $62 \%$ reduced motility at $8^{\circ} \mathrm{C}$ [53]. A similar reduction in motility was observed for the $\triangle r p o Q$ using the same temperature and salt concentration [33]. RpoQ is similar to other sigma factors that functions as a gene activator, and most probably activates a regulator of fla $A$ gene. In $V$. cholerae it was show that fla $A$ transcription is regulated by sigma factor 54 which depends on and requires an additional regulator, $\operatorname{FlrC}[54,55]$. Thus, it is reasonable to speculate that RpoQ may work in the similar manner as $V$. cholerae by activating regulators responsible for motility, where in the $\triangle r p o Q$ mutant, fla $A$ regulator is not activated resulting in decreased motility.

The quorum sensing master regulator LitR, has been shown to be associated with motility in A. salmonicida similar to other bacteria $[27,56]$. The deletion of litR $(\triangle l i t R)$ resulted in more motile strain than the wild-type [27]. This led us to conclude that LitR is a repressor of motility at HCD, where its deletion ( $\triangle$ litR) mimics the low cell density phenotype [27]. A similar conclusion was also applied to the role of RpoQ in motility [33]. However, $\triangle r p o Q$ transcriptome exhibited downregulation in motility genes regardless of growth phases. This proposes either that QS does not seem to be implicated in the RpoQ-dependent induction of motility and chemotaxis, or that rpoQ is critical for flagellar gene expression, where its deletion does not completely mimic the low cell density phenotype.

In summary, these results indicate the importance of RpoQ in controlling the flaA gene which has a direct impact on the motility. Additionally RpoQ seems to tightly regulates several genes essential for flagellar assembly of $A$. salmonicida. Furthermore, RpoQ is believed to be a stress regulator in A. salmonicida similar to RpoS which may have the ability to switch between motile and non-motile states in response to physical or chemical changes in the environment.

\section{LitR and RpoQ repress genes associated with virulence}

Among the differentially expressed transcripts of $\triangle r p o Q$ and $\Delta l i t R$ we were able to identify a number of significantly upregulated genes that may play an important role in virulence. These included the genes encoding adhesion and fimbrial attachment proteins also known as tad genes or tad operon. Tad loci is a widespread colonization island that is found in numerous pathogenic and non pathogenic bacteria including vibrios such as V. cholerae, A. fischeri, V.vulnificus and Vibrio parahaemolyticus ( $V$. parahaemolyticus) [36, 57]. The A. salmonicida genome encode a number of potential virulence factors. Among them is the Flp-type pilus (fimbrial -low molecular weight protein), which has high similarity to the Tad macromolecular transport system of Actinobacillus actinomycetemcomitans (A. actinomycetemcomitans) [36]. Tad operon is known to facilitate adhesion and, to play an important role in motility and biofilm formation [57]. Although the function of the tad operon was not investigated in detail in A. salmonicida and the inactivation of two tad genes (VSAL_IIO367 and VSAL_IIO368) did not affect the architecture or amounts of biofilm formed [19], it is reasonable to assume that this widespread colonization island provides important functions for pathogenic bacteria (e.g., A. salmonicida) in the form of colonization and adhesion. Our previous microarray analyzes on the $\Delta l i t R$ mutant did not reveal any tad genes to be differentially expressed [19], although the adhesion of the $\Delta l i t R$ mutants to the agar plates was observed [27]. In the study presented here, DEGs related to Tad locus in $\triangle r p o Q$ and $\triangle l i t R$ yielded highly similar findings, where a number of tad genes were significantly upregulated. Whereas, the transcriptome of A salmonicida wild-type at HCD revealed opposite results, where tad genes were downregulated. Thus, the increased expression level of LitR and RpoQ at HCD, leads to a repression of tad genes in A. salmonicida wild-type. This, proposes the importance of this colonization island at early stages of life cycle (i.e., LCD). Although evidence for the physiological role of this colonization island in Vibrionaceae is scant, recently a correlation between tad genes and phenotypes in $V$. vulnificus was found to be associated with biofilm formation, auto-aggregation and initial surface attachment to the host [58]. tad genes were also found to mediate adherence, colonization and micro-colony formation in other bacteria [59-61]. Hypothetically, these findings also can be considered in A. salmonicida, where the tad operon is mainly required for the initial surface attachment of the cells to the biotic surface and formation of micro-colonies and less necessary in the later stages of biofilm or infection. However, further investigations are needed to confirm this hypothesis.

Biofilm formation and colony rugosity are low cell density phenotypes involving expression of syp

The ability to form rugose colonies and biofilm are often correlated features in vibrios, which is generally associated with enhanced production of exopolysaccharides [21, 25, 62]. Similarly, in A. salmonicida colony rugosity and biofilm formation requires the expression of syp genes responsible for the production of EPS [19, 33]. Our previous microarray analysis showed that the expression of 14 out of 18 syp genes was negatively regulated by LitR, where the majority, were genes significantly upregulated in the biofilm compared to the 
suspension [19]. However, the data obtained from the current work did not show significant upregulation of the 14 syp genes previously identified [19], except sypA and sypC genes, that showed to be differentially expressed at HCD. We know from our previous results that changes in medium composition affects the biofilm morphology [19], and here we assume that changes in some compounds of the SWT medium have affected the transcriptome of $\Delta l i t R$ and resulted in less differentially expressed syp genes. In contrast to the $\Delta l i t R$ transcriptome, the $\triangle r p o Q$ presented an upregulation among 13 out of 18 syp genes at HCD. We have previously observed what we refere to as a "late and weak" wrinkling colony morphology exhibited by $\Delta$ litR compared to $\triangle r p o Q$, which demonstrated an earlier and stronger rugosity in addition to a heavy and slimy extracellular matrix substance in the biofilm [33]. This led us to propose that LitR performs its activity on syp through RpoQ, where its expression leads to a strong syp repression. Moreover, the mature biofilm formation exhibited by $\Delta l i t R$ was proposed to be a result of two independent processes where the first results in repression of syp via RpoQ while the second is independent of rpoQ and represses other biofilm matrix components. When three syp genes were inactivated separately in the rpoQ mutant no biofilm and no wrinckeled colonies were formed, and the $\Delta r p o Q s y p$ double mutants behaved similar to the wild-type (Additional file 10: Figure S1). However, the inactivation of the same syp genes in $\Delta l i t R$, resulted in some biofilm production using the same conditions [19]. Hence, the inactivation of syp genes in $\triangle r p o Q$ mutant inhibited colony rugosity and biofilm formation completely, which was not the case for the $\Delta l i t R$. Consequently, our results provide a clear evidence that the negative regulatory cascade from LitR to syp genes is operated through RpoQ in a cell density dependent manner. Why is RpoQ involved in regulating exopolysaccharide production via syp? The bacteria, whether it is in the host or in the aquatic environment, employes survival strategies, where sigma factors (e.g., RpoS or RpoQ) are believed to aid in adaptation to environmental stress such as osmotic shock and starvation [63]. Hence, for RpoQ to be involved in regulating this EPS locus (syp operon) may suggest that this sigma factor may play an important role in environmental persistence protecting the bacteria under starvation and during infection of the host. We therefore believe that in addition to the negative regulatory cascade operated from LitR to syp genes (via RpoQ), rpoQ is also influenced by other genes and environmental factors leading to repression of syp in a pathway that remains unknown (Fig. 7).

Even though the relationship between RpoQ and LitR is not well-studied in A. salmonicida, our current

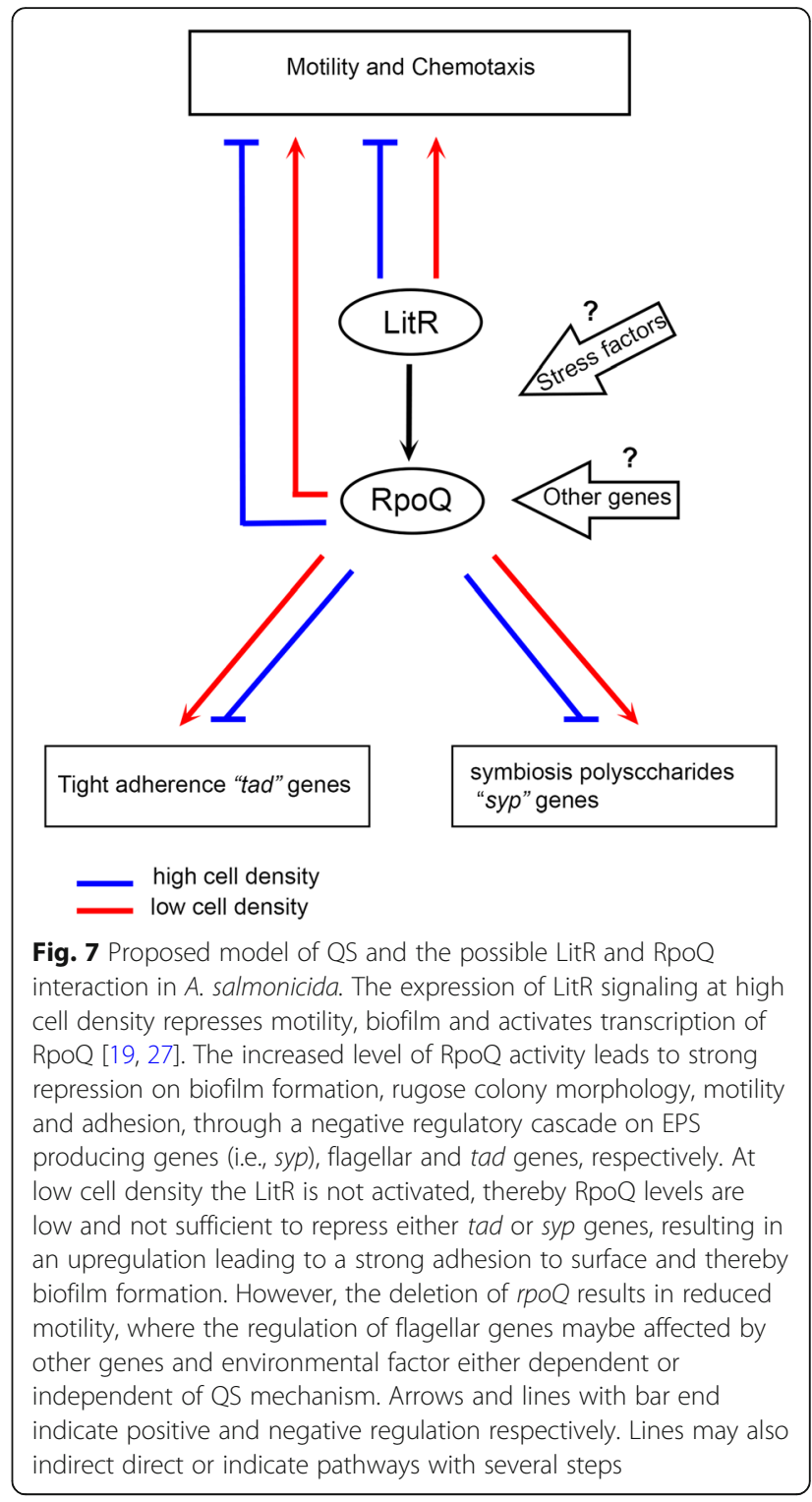

transcriptome and previous microarray data showed a positive regulation of LitR on $r p o Q$, confirming that RpoQ operates downstream of LitR in the QS regulatory hierarchy [19]. Furthermore, the overexpression of rpoQ in the $\Delta$ litR mutant influenced phenotypes related to QS [33]. Consistent with the results demonstrated in $A$. fischeri, where the overexpression of RpoQ in $\Delta l i t R$ mutant resulted in decreased motility [32].

Taken together, our data suggest a working model (Fig. 7) for how LitR and RpoQ work together in A. salmonicida, proposing that expression of genes in A. salmonicida is not always regulated by QS, and possibly involve other regulatory elements that act independently of the QS regulatory mechanism. Hence, the interaction between RpoQ and LitR and their roles in controlling motility, biofilm formation and rugose colony morphology, 
may be directly or indirectly regulated by RpoQ independent of LitR and vice versa. Additionally, we assume that RpoQ is regulated by other gene(s) and stress factors rather than LitR alone.

\section{Conclusion}

In this work we have shown that the master regulator LitR and the alternative sigma factor RpoQ regulate genes involved in motility, rugose colony morphology and biofilm formation in A. salmonicida. Our results indicate that RpoQ is an activator of flaA gene either directly or indirectly. Moreover, the positive activation of LitR on $r p o Q$ results in reduced motility, repression of genes involved in adhesion (e.g., tad genes) and exopolysaccharide production via syp operon at $\mathrm{HCD}$ in $A$. salmonicida wild-type. These findings confirm that LitR and RpoQ regulate phenotypic traits related to QS together (dependent) and also independent of each other, where other environmental factors and genes are probably also involved. However further studies are needed to map the elements and factors affecting gene expression and influencing the observed phenotypes during different life cycles.

\section{Additional files}

Additional file 1: Table S1. The table lists the summary of RNA sequencing data for A. salmonicida LFI1238, $\Delta$ litR and $\Delta r p o Q$. (XLSX $10 \mathrm{~kb}$ )

Additional file 2: Table $\mathbf{S 2}$. The table lists the differentially expressed genes of A. salmonicida wild-type at HCD compared to LCD. (XLSX $82 \mathrm{~kb}$ ) Additional file 3: Table S3. The table lists the functional distribution of the differenatially expressed gene of $A$. salmonicida at HCD relative to LCD. (DOCX $16 \mathrm{~kb})$

Additional file 4: Table S4. The table lists the differentially expressed genes of $\Delta$ litR mutant compared to wild-type at LCD. (XLSX $13 \mathrm{~kb}$ )

Additional file 5: Table S5. The table lists the differentially expressed genes of $\Delta$ litR mutant compared to wild-type at HCD. (XLSX $24 \mathrm{~kb}$ )

Additional file 6: Table S6 and Table S7. The tables list the functional distribution of $\Delta /$ litR/wt at LCD and HCD. (DOCX $18 \mathrm{~kb}$ )

Additional file 7: Table S8. The table lists the differentially expressed genes of $\triangle r p o Q$ mutant compared to wild-type at LCD. (XLSX $15 \mathrm{~kb}$ )

Additional file 8: Table S9. The table lists the differentially expressed genes of $\triangle r p o Q$ mutant compared to wild-type at HCD. (XLSX $28 \mathrm{~kb}$ )

Additional file 9: Table S10 and Table S11. The tables list the functional distribution of $\triangle$ rpoQ/wt at LCD and HCD. (DOCX $18 \mathrm{~kb}$ )

Additional file 10: Figure S1. Colony morpgology and biofilm formation of $\triangle r p o Q$ and LFI1238 syp mutants. (DOCX $1263 \mathrm{~kb}$ )

Additional file 11: Table S12. The table lists the differentially expressed genes of $\triangle r p o Q$ compared to $\triangle$ litR at LCD. (XLSX $19 \mathrm{~kb}$ )

Additional file 12: Table S13. The table lists the differentially expressed genes of $\Delta r p o Q$ compared to $\Delta$ litR at HCD. (XLSX $17 \mathrm{~kb}$ )

\section{Abbreviations}

DEGs: Differentially expressed genes; EPS: Exopolysaccharide; HCD: High cell density; LCD: Low cell density; min: Minutes; $\mathrm{OD}_{600}$ : Optical density measured at 600 nm; ON: Overnight; QS: Quorum sensing; rpm: Rounds per minute

\section{Acknowledgements}

We thank Dr. Eric V. Stabb (University of Georgia) for the pVSV102 and pEVS104 plasmids. We also thank researcher Adele Kim Willamson (UiT The Arctic University of Norway) for proofreading the manuscript.

\section{Funding}

This work was financed by UiT The Arctic University of Norway. The publication charges have been funded by a grant from the publication fund of UiT The Arctic University of Norway. The funders had no role in study design, data collection and analysis, decision to publish, or preparation and writing of the manuscript.

\section{Availability of data and materials}

All data generated or analysed during this study are included in this published article and its supplimentary materials. The transcriptome data have been deposited to the European Nucleotide Archive (www.ebi.ac.uk/ ena) under study accession number PRJEB28385.

\section{Author's contributions}

MK, NPW, and HH conceived and designed the experiments. MK and $\mathrm{HH}$ constructed the mutants. MK performed the experiments and analyzed the transcriptomics data. EH analyzed the transcriptomics data. MK and NP wrote the paper. NP coordinated the research. All authors read and approved the final manuscript.

Ethics approval and consent to participate

Not applicable

\section{Consent for publication}

Not applicable.

\section{Competing interests}

The authors declare that they have no competing interest.

\section{Publisher's Note}

Springer Nature remains neutral with regard to jurisdictional claims in published maps and institutional affiliations.

\section{Author details}

${ }^{1}$ Norwegian Structural Biology Centre, UiT - The Arctic University of Norway, N-9037 Tromsø, Norway. ${ }^{2}$ Centre for Bioinformatics, Department of Chemistry, Faculty of Science and Technology, UiT - The Arctic University of Norway, N-9037 Tromsø, Norway.

Received: 28 September 2018 Accepted: 11 March 2019

Published online: 15 March 2019

References

1. Miller MB, Bassler BL. Quorum sensing in bacteria. Annu Rev Microbiol. 2001; 55:165-99.

2. Bassler BL. How bacteria talk to each other: regulation of gene expression by quorum sensing. Curr Opin Microbiol. 1999;2(6):582-7.

3. Ng WL, Bassler BL. Bacterial quorum-sensing network architectures. Annu Rev Genet. 2009:43:197-222.

4. Parsek MR, Greenberg EP. Sociomicrobiology: the connections between quorum sensing and biofilms. Trends Microbiol. 2005;13(1):27-33.

5. Li YH, Tian X. Quorum sensing and bacterial social interactions in biofilms. Sensors (Basel). 2012:12(3):2519-38.

6. Waters CM, Bassler BL. Quorum sensing: cell-to-cell communication in bacteria. Annu Rev Cell Dev Biol. 2005:21:319-46.

7. Johnson CN. Fitness factors in vibrios: a mini-review. Microb Ecol. 2013;65(4): 826-51.

8. Milton DL. Quorum sensing in vibrios: complexity for diversification. Int J of Med Microbiol. 2006;296(2-3):61-71.

9. Hansen H, Purohit AA, Leiros HK, Johansen JA, Kellermann SJ, Bjelland AM, Willassen NP. The autoinducer synthases LuXI and AinS are responsible for temperature-dependent AHL production in the fish pathogen Alivibrio salmonicida. BMC Microbiol. 2015;15:69.

10. Zhu S, Kojima S, Homma M. Structure, gene regulation and environmental response of flagella in Vibrio. Front Microbiol. 2013;4:410. 
11. McCarter LL. Polar flagellar motility of the Vibrionaceae. Microbiol Mol Biol Rev. 2001;65(3):445-62 table of contents.

12. Guttenplan SB, Kearns DB. Regulation of flagellar motility during biofilm formation. FEMS Microbiol Rev. 2013;37(6):849-71.

13. Donlan RM, Costerton JW. Biofilms: survival mechanisms of clinically relevant microorganisms. Clin Microbiol Rev. 2002;15(2):167-93.

14. Yildiz FH, Visick KL. Vibrio biofilms: so much the same yet so different. Trends Microbiol. 2009;17(3):109-18.

15. Nistico L, Gieseke A, Stoodley P, Hall-Stoodley L, Kerschner JE, Ehrlich GD. Fluorescence "in situ" hybridization for the detection of biofilm in the middle ear and upper respiratory tract mucosa. Methods Mol Biol. 2009;493: $191-213$.

16. Jamal M, Ahmad W, Andleeb S, Jalil F, Imran M, Nawaz MA, Hussain T, Ali M, Rafiq M, Kamil MA. Bacterial biofilm and associated infections. J Chin Med Assoc. 2018;81(1):7-11.

17. Klausen M, Aaes-Jorgensen A, Molin S, Tolker-Nielsen T. Involvement of bacterial migration in the development of complex multicellular structures in Pseudomonas aeruginosa biofilms. Mol Microbiol. 2003;50(1):61-8.

18. Gupta P, Sarkar S, Das B, Bhattacharjee S, Tribedi P. Biofilm, pathogenesis and prevention--a journey to break the wall: a review. Arch Microbiol. 2016; 198(1):1-15.

19. Hansen $H$, Bjelland AM, Ronessen M, Robertsen E, Willassen NP. LitR is a repressor of syp genes and has a temperature-sensitive regulatory effect on biofilm formation and colony morphology in Vibrio (Aliivibrio) salmonicida. Appl Environ Microbiol. 2014;80(17):5530-41.

20. Yip ES, Geszvain K, DeLoney-Marino CR, Visick KL. The symbiosis regulator rscS controls the syp gene locus, biofilm formation and symbiotic aggregation by Vibrio fischeri. Mol Microbiol. 2006;62(6):1586-600.

21. Yildiz FH, Schoolnik GK. Vibrio cholerae O1 El Tor: identification of a gene cluster required for the rugose colony type, exopolysaccharide production, chlorine resistance, and biofilm formation. Proc Natl Acad Sci U S A. 1999; 96(7):4028-33.

22. Fong JC, Syed KA, Klose KE, Yildiz FH. Role of Vibrio polysaccharide (vps) genes in VPS production, biofilm formation and Vibrio cholerae pathogenesis. Microbiology. 2010;156(Pt 9:2757-69.

23. Beyhan S, Odell LS, Yildiz FH. Identification and characterization of cyclic diguanylate signaling systems controlling rugosity in Vibrio cholerae. J Bacteriol. 2008;190(22):7392-405.

24. Waters CM, Lu W, Rabinowitz JD, Bassler BL. Quorum sensing controls biofilm formation in Vibrio cholerae through modulation of cyclic di-GMP levels and repression of vpsT. J Bacteriol. 2008;190(7):2527-36.

25. Yildiz FH, Liu XS, Heydorn A, Schoolnik GK. Molecular analysis of rugosity in a Vibrio cholerae O1 El Tor phase variant. Mol Microbiol. 2004;53(2):497-515.

26. Hammer BK, Bassler BL. Quorum sensing controls biofilm formation in Vibrio cholerae. Mol Microbiol. 2003;50(1):101-4.

27. Bjelland AM, Sørum H, Tegegne DA, Winther-Larsen HC, Willassen NP, Hansen $\mathrm{H}$. LitR of Vibrio salmonicida is a salinity-sensitive quorum-sensing regulator of phenotypes involved in host interactions and virulence. Infect Immun. 2012;80(5):1681-9.

28. Fidopiastis PM, Miyamoto CM, Jobling MG, Meighen EA, Ruby EG. LitR, a new transcriptional activator in Vibrio fischeri, regulates luminescence and symbiotic light organ colonization. Mol Microbiol. 2002;45(1):131-43.

29. Lee JH, Rhee JE, Park U, Ju HM, Lee BC, Kim TS, Jeong HS, Choi SH. Identification and functional analysis of vibrio vulnificus SmcR, a novel global regulator. J Microbiol Biotechnol. 2007;17(2):325-34.

30. McCarter LL. OpaR, a homolog of Vibrio harveyi LuxR, controls opacity of Vibrio parahaemolyticus. J Bacteriol. 1998;180(12):3166-73.

31. Enos-Berlage JL, McCarter LL. Relation of capsular polysaccharide production and colonial cell organization to colony morphology in Vibrio parahaemolyticus. J Bacteriol. 2000;182(19):5513-20.

32. Cao X, Studer SV, Wassarman K, Zhang Y, Ruby EG, Miyashiro T. The novel sigma factor-like regulator RpoQ controls luminescence, chitinase activity, and motility in Vibrio fischeri. mBio. 2012;3(1):e00285-11.

33. Khider $\mathrm{M}$, Willassen NP, Hansen $\mathrm{H}$. The alternative sigma factor RpoQ regulates colony morphology, biofilm formation and motility in the fish pathogen Aliivibrio salmonicida. BMC Microbiol. 2018;18(1):116.

34. Magoc T, Wood D, Salzberg SL. EDGE-pro: estimated degree of gene expression in prokaryotic genomes. Evol Bioinformatics Online. 2013;9: 127-36.

35. Love Ml, Huber W, Anders S. Moderated estimation of fold change and dispersion for RNA-seq data with DESeq2. Genome Biol. 2014;15(12):550.
36. Hjerde E, Lorentzen MS, Holden MT, Seeger K, Paulsen S, Bason N, Churcher C, Harris D, Norbertczak H, Quail MA, et al. The genome sequence of the fish pathogen Aliivibrio salmonicida strain LFI1238 shows extensive evidence of gene decay. BMC Genomics. 2008;9:616.

37. Dunn AK, Millikan DS, Adin DM, Bose JL, Stabb EV. New rfp- and pES213derived tools for analyzing symbiotic Vibrio fischeri reveal patterns of infection and lux expression in situ. Appl Environ Microbiol. 2006;72(1):802-10.

38. Serres MH, Riley M. Multifun, a multifunctional classification scheme for Escherichia coli K-12 gene products. Microb Comp Genomics. 2000;5(4):205-22.

39. Hoff KA. Survival of Vibrio anguillarum and Vibrio salmonicida at different salinities. Appl Environ Microbiol. 1989;55(7):1775-86.

40. Colquhoun DJ, Sørum H. Cloning, characterisation and phylogenetic analysis of the fur gene in Vibrio salmonicida and Vibrio logei. Gene. 2002; 296(1-2):213-20.

41. Kashulin A, Seredkina N, Sørum H. Cold-water vibriosis. The current status of knowledge. J Fish Dis. 2017;40(1):119-26.

42. Buchholtz C, Nielsen KF, Milton DL, Larsen JL, Gram L. Profiling of acylated homoserine lactones of Vibrio anguillarum in vitro and in vivo: influence of growth conditions and serotype. Syst Appl Microbiol. 2006;29(6):433-45.

43. Zhu J, Miller MB, Vance RE, Dziejman M, Bassler BL, Mekalanos JJ. Quorumsensing regulators control virulence gene expression in Vibrio cholerae. Proc Natl Acad Sci U S A. 2002;99(5):3129-34.

44. Klose KE, Mekalanos JJ. Differential regulation of multiple flagellins in Vibrio cholerae. J Bacteriol. 1998;180(2):303-16.

45. Hulsmann A, Rosche TM, Kong IS, Hassan HM, Beam DM, Oliver JD. RpoSdependent stress response and exoenzyme production in Vibrio vulnificus. Appl Environ Microbiol. 2003;69(10):6114-20.

46. Moorthy S, Watnick PI. Identification of novel stage-specific genetic requirements through whole genome transcription profiling of Vibrio cholerae biofilm development. Mol Microbiol. 2005;57(6):1623-35.

47. Moorthy S, Watnick PI. Genetic evidence that the Vibrio cholerae monolayer is a distinct stage in biofilm development. Mol Microbiol. 2004;52(2):573-87.

48. Bjelland AM, Johansen R, Brudal E, Hansen $H$, Winther-Larsen $H C$, Sørum $H$. Vibrio salmonicida pathogenesis analyzed by experimental challenge of Atlantic salmon (Salmo salar). Microbial Pathog. 2012;52(1):77-84.

49. Karlsen C, Paulsen SM, Tunsjo HS, Krinner S, Sørum H, Haugen P, Willassen NP. Motility and flagellin gene expression in the fish pathogen Vibrio salmonicida: effects of salinity and temperature. Microb Pathog. 2008;45(4): 258-64.

50. Egidius EWR, Andersen K, Hoof KA, Hjeltnes B. Vibrio salmonicida sp. nov., a new fish pathogen. Int J Syst Bacteriol. 1986;36:518-20.

51. Macnab RM. How bacteria assemble flagella. Annu Rev Microbiol. 2003;57: 77-100.

52. Millikan DS, Ruby EG. Vibrio fischeri flagellin a is essential for normal motility and for symbiotic competence during initial squid light organ colonization. J Bacteriol. 2004;186(13):4315-25.

53. Norstebø SF, Paulshus E, Bjelland AM, Sørum H. A unique role of flagellar function in Aliivibrio salmonicida pathogenicity not related to bacterial motility in aquatic environments. Microbial Pathog. 2017;109:263-73.

54. Syed KA, Beyhan S, Correa N, Queen J, Liu J, Peng F, Satchell K, Yildiz F, Klose KE. The Vibrio cholerae flagellar regulatory hierarchy controls expression of virulence factors. J Bacteriol. 2009;191(21):6555-70.

55. Correa NE, Lauriano CM, McGee R, Klose KE. Phosphorylation of the flagellar regulatory protein FIrC is necessary for Vibrio cholerae motility and enhanced colonization. Mol Microbiol. 2000;35(4):743-55.

56. Kim SM, Lee DH, Choi SH. Evidence that the Vibrio vulnificus flagellar regulator FlhF is regulated by a quorum sensing master regulator SmcR. Microbiology. 2012;158(Pt 8:2017-25.

57. Tomich M, Planet PJ, Figurski DH. The tad locus: postcards from the widespread colonization island. Nat Rev Microbiol. 2007;5(5):363-75.

58. Pu M, Rowe-Magnus DA. A tad pilus promotes the establishment and resistance of Vibrio vulnificus biofilms to mechanical clearance. NPJ Biofilms Microbiomes. 2018;4:10.

59. Nika JR, Latimer JL, Ward CK, Blick RJ, Wagner NJ, Cope LD, Mahairas GG, Munson RS Jr, Hansen EJ. Haemophilus ducreyi requires the flp gene cluster for microcolony formation in vitro. Infect Immun. 2002;70(6):2965-75.

60. Watnick PI, Kolter R. Steps in the development of a Vibrio cholerae El Tor biofilm. Mol Microbiol. 1999;34(3):586-95.

61. O'Toole GA, Kolter R. Flagellar and twitching motility are necessary for Pseudomonas aeruginosa biofilm development. Mol Microbiol. 1998;30(2): 295-304. 
62. Casper-Lindley C, Yildiz FH. VpsT is a transcriptional regulator required for expression of vps biosynthesis genes and the development of rugose colonial morphology in Vibrio cholerae O1 El Tor. J Bacteriol. 2004;186(5): 1574-8.

63. Trastoy R, Manso T, Fernandez-Garcia L, Blasco L, Ambroa A, Perez Del Molino ML, Bou G, Garcia-Contreras R, Wood TK, Tomas M. Mechanisms of bacterial tolerance and persistence in the gastrointestinal and respiratory environments. Clin Microbiol Rev. 2018;31(4).

64. Stabb EV, Ruby EG. RP4-based plasmids for conjugation between Escherichia coli and members of the Vibrionaceae. Methods Enzymol. 2002; 358:413-26.

Ready to submit your research? Choose BMC and benefit from:

- fast, convenient online submission

- thorough peer review by experienced researchers in your field

- rapid publication on acceptance

- support for research data, including large and complex data types

- gold Open Access which fosters wider collaboration and increased citations

- maximum visibility for your research: over $100 \mathrm{M}$ website views per year

At BMC, research is always in progress.

Learn more biomedcentral.com/submissions 